\title{
Acetylcholine Receptor Aggregation at Nerve-Muscle Contacts in Mammalian Cultures: Induction by Ventral Spinal Cord Neurons Is Specific to Axons
}

\author{
E. K. Dutton,, ${ }^{1, a}$ C.-S. Uhm, ${ }^{1}$ S. J. Samuelsson, ${ }^{1, b}$ A. E. Schaffner, ${ }^{2}$ S. C. Fitzgerald, ${ }^{3}$ and M. P. Daniels ${ }^{1}$ \\ 'Laboratory of Biochemical Genetics, National Heart, Lung, and Blood Institute, 'Laboratory of Neurophysiology, \\ National Institute of Neurological Disorders and Stroke, and 'Laboratory of Developmental Neurobiology, National \\ Institute of Child Health and Human Development, National Institutes of Health, Bethesda, Maryland 20892
}

\begin{abstract}
We used a novel mammalian coculture system to study $A C h$ receptor (AChR) redistribution and synaptic structure at nerve-muscle contacts. Ventral spinal cord (VSC) neurons were plated on cultures containing extensive myotubes but few flbroblasts. Neurite-induced redistribution of AChRs occurred within $6 \mathrm{hr}$ after plating neurons and was maximal between 36-48 hr. This $A C h R$ redistribution appeared in two patterns: (1) AChR density at sites directly apposed to the neurite where neurites crossed preexisting AChR patches was sharply reduced, (2) Newly aggregated AChRs formed swaths lateral to the neurite path. VSC neurons induced more AChR aggregation than hippocampal, superior cervical ganglion and dorsal root ganglion neurons. The 43 and $58 \mathrm{kDa}$ postsynaptic proteins were colocalized with AChR-enriched domains in all VSC neurite-induced aggregates whereas the colocalization of laminin was variable. Electron microscopy of regions with neuriteinduced AChR aggregation showed postsynaptic membrane specializations characteristic of developing synapses and, in older cultures, features of more mature synaptic structure. Thus, the coculture system is useful for studying early stages of neuromuscular junction (NMJ) formation. Neurites in these cocultures were identified as axons or dendrites by morphological criteria and by their immunoreactivity for synaptophysin and phosphorylated heavy neurofilament subunits or for microtubule associated protein 2 (MAP2), respectively. Axons showed a 10-fold higher induction of AChR aggregation than did dendrites. Thus, at least one essential signaling molecule necessary for the induction of AChR aggregation at sites of interaction with muscle appears to be expressed in a polarized fashion in developing VSC neurons.
\end{abstract}

[Key words: neuromuscular junction, ACh receptor, skeletal muscle, synapse, spinal cord neuron, cell culture, axon, dendrite]

\footnotetext{
Received Mar. 3, 1995; revised July 7, 1995; accepted July 13, 1995.

We thank Dr. Evelyn Ralston for a critical reading of the manuscript, Dr. Yuan Liu for providing SCG neurons and Catherine Mueller, Linda Tang, and Edward Foster for technical assistance.

Correspondence should be addressed to Dr. Mathew P. Daniels, Laboratory of Biochemical Genetics, NIH, Building 36, Roum IC06, Bethesda, MD 20892.

Present address: Hoechst-Roussel Pharmaceuticals Inc., P.O. Box 2500, Route 202-206, Somerville, NJ 08876.

Present address: Proctor and Gamble Pharmaceuticals, P.O. Box 191, Nor wich, NY 13815.

Copyright 1995 Society for Neuroscience $0270-6474 / 95 / 157401-16 \$ 05.00 / 0$
}

Interactions between nerve and muscle during synaptogenesis elicit the formation of membrane specializations that are required for efficient synaptic transmission (Hall and Sanes, 1993). Much that we know about these interactions has come from culture systems, especially those using chick and Xenopus cells. In these cocultures, cholinergic neurons form functional synapses with skeletal muscle cells (Hall and Sanes, 1993), and these synaptic sites are associated with $\mathrm{ACh}$ receptor (AChR) aggregates (Anderson and Cohen, 1977; Frank and Fischbach, 1979; Kidokoro et al., 1980; Role et al., 1985) that form over a time course consistent with that in vivo (Cohen et al., 1979; Kidokoro et al., 1980; Role et al., 1987). Similarly, nerve-muscle synapse formation in culture involves the formation of a specialized extracellular matrix (ECM), (Anderson and Fambrough, 1983; Davey and Cohen, 1986; Cohen and Godfrey, 1992; Lieth and Fallon, 1993) and structural as well as molecular specialization of the nerve terminal, postsynaptic sarcolemma and cytoskeleton (Shimada et al., 1969; Weldon and Cohen, 1979; Nakajima et al., 1980; Peng et al., 1980; Froehner, 1993).

Despite all the information obtained with culture systems, much remains unknown about the inductive signals and responses leading to synaptic differentiation (Hall and Sanes, 1993). Neuromuscular junction (NMJ) development in vivo has been most thoroughly examined in the rat and an abundance of immunological and genetic probes are available for this species. However, cocultures of rat or mouse muscle and nerve cells have not been used extensively to study the early events in neuromuscular synapse formation. This may be due to the paucity of nerve contact-induced $\mathrm{AChR}$ aggregation observed in a time frame comparable to the early course of synapse formation in vivo (Kidokoro et al., 1976; Kidokoro, 1980; but see Lupa et al., 1990). It seemed possible that nerve-muscle interactions in these cocultures were impeded by the fibroblasts and other nonmuscle cells that can envelop the myotubes (Olek et al., 1986). Thus, we have developed a mammalian coculture system based on the addition of ventral spinal cord (VSC) neurons to cultures containing extensive myotubes and few nonmuscle cells (Daniels, 1990). We have found that neurites of VSC neurons induce a rapid, extensive aggregation of AChRs along the sites of ncurite-muscle contact and that these sites contain molecular and structural specializations similar to those of developing synapses in vivo.

Developing motor neurons generate dendritic trees as well as long axons, but only the axons grow out of the spinal cord to innervate muscle. This is a striking example of the cellular po- 
larity of neurons observed in vivo and in vitro (Craig and Banker, 1994). However, it has not been determined whether the specific molecular components involved in the establishment of nerve-muscle contacts and the formation of NMJs are targeted to developing axons and excluded from dendrites. Here, we have characterized the neurites in our coculture system by morphology and immunocytochemistry and have found that the induction of AChR aggregation by neurite contact is specific to developing axons.

\section{Materials and Methods}

Cell culture. Cultures enriched in myotubes were obtained essentially as described (Daniels, 1990). Briefly, cells were obtained by trypsinization of $21 \mathrm{~d}$ old fetal rat hindlimb muscles (Schaffner and Daniels, 1982) except that preplating was done for $40 \mathrm{~min}$ in a $100 \mathrm{~mm}$ tissue culture dish. Cells were plated in $100 \mathrm{~mm}, 0.5 \%$ gelatin-coated tissue culture dishes $(3.5 \times 106$ cells per dish) in medium containing $80 \%$ Dulbecco's modified Eagle's medium (DMEM; GIBCO, Grand Island Biochemical Co., Grand Island, NY), 10\% fetal calf serum (FCS, GIB$\mathrm{CO}$ ) and $10 \%$ horse serum (HS, GIBCO). Approximately $48 \mathrm{hr}$ after plating, myoblasts were selectively detached from the culture dishes by incubation with a neutral protease (Dispase, Grade II, Boehringer Mannheim Biochemicals, Indianapolis, IN) at $0.025-0.05 \%$ in calcium-free Dulbecco's phosphate-buffered saline (DPBS), collected and replated at a density of $3.75-5.0 \times 10^{4}$ cells per $13 \mathrm{~mm}$ glass coverslip coated with carbon and gelatin. Two days after replating, the cells were fed with DMEM, $10 \%$ HS, $1.5 \mu \mathrm{M}$ tetrodotoxin (TTX, to inhibit myotube contraction), penicillin/streptomycin (P/S, $100 \mathrm{U} / 100 \mathrm{mg} / \mathrm{ml}$ ), Fungizone $(2.5 \mu \mathrm{g} / \mathrm{ml})$ and $10 \mu \mathrm{M}$ cytosine arabinoside (to kill dividing cells). Neurons were plated on these myotube cultures $24-48$ hr later and most cultures were processed or observed within the next $2 \mathrm{~d}$.

Cell suspensions from neural tissues were prepared as follows: ventral halves of spinal cords of d13.5 mouse or d16-17 rat fetuses were dissociated with trypsin or papain, respectively (Guthrie et al., 1987; Walton et al.. 1993); superior cervical ganglia (SCG) of d 13.5 mouse fetuses were dissociated with trypsin (H1ggins et al,, 1991; cells generously provided by Dr. Yuan Liu, National Institutes of Health, Bethesda, MD); dorsal root ganglia (DRG) of d13.5 mouse fetuses were dissociated with trypsin (Fitzgerald, 1989) and hippocampi of d18 rat fetuses (Goslin and Banker, 1991) were dissociated with papain. VSC neurons used for studies involving the properties of axons and dendrites were obtained from d 16 rat fetuses as described by Walton et al. (1993). Neurons were added to the muscle cell cultures by moving the coverslips to a dry tissue culture dish and immediately adding $50 \mu \mathrm{l}$ of cell suspension to which $1.5 \mu \mathrm{M}$ TTX had been added. The number of cells per coverslip from the different neuronal sources was adjusted to yield a similar extent of neurite outgrowth after $24 \mathrm{hr}$ in culture: 50,000 for VSC and hippocampus, 5000 for SCG, and 2000 for DRG. After incubation for $2-3 \mathrm{hr}$ to allow for adhesion of neurons, $1.5 \mathrm{ml}$ of the appropriate culture medium was added to the dishes. Eagle's Minimum Essential Medium (GIBCO) plus 5\% HS supplemented with I-glutamine $(2 \mathrm{~mm})$, and TTX, P/S, and Fungizone at the above stated concentrations was used for VSC and hippocampal cultures. SCG and DRG cultures were maintained in the above medium with the addition of nerve growth factor $(30 \mathrm{ng} / \mathrm{ml})$.

AChR and immunofluorescence labeling. AChRs were labeled by incubating cultures with $5 \times 10^{*} \mathrm{M}$ tetramethylrhodamine-conjugated $\alpha$-bungarotoxin (TRITC-BTX; Molecular Probes, Eugene OR), for $1 \mathrm{hr}$ at $37^{\circ} \mathrm{C}$. For prelabeling experiments, AChRs were labeled with TRITCBTX prior to neuron plating for $1 \mathrm{hr}$ at $37^{\circ} \mathrm{C}$, rinsed, and returned (after adding the neurons) to the incubator for a total coculture period of 18 hr. The cultures were then fixed and the neurites labeled as described below. Under these conditions, there was approximately a $50 \%$ loss of the TRITC-BTX cell surface label due to AChR turnover (see Salpeter et al., 1982). To limit the disturbance of the cultures before fixation, they were rinsed gently by dipping the coverslips once in DMEM buffered with $N$-2-hydroxyethyl piperazine- $N$-2-ethanesulfonic acid (Hepes) with $1 \%$ BSA and $1.5 \mu \mathrm{M}$ TTX (Med-A) and then placing them into a second dish of the same medium for $15 \mathrm{~min}$ at room temperature with occasional rocking. The cultures were then briefly rinsed the same way in Med-A without the BSA and fixed by gradual replacement of the medium with $2 \%$ paraformaldehyde in $0.1 \mathrm{M}$ sodium phosphate buffer, $\mathrm{pH} 7.2$. After complete replacement with $2 \%$ paraformaldehyde, fixation was continued for $30 \mathrm{~min}$ at room temperature. In experiments where the specificity of a monoclonal antibody for a phosphorylated epitope of the neurofilament high molecular weight subunit (neurofilament $H$ ) was important, Hepes buffer was used in the fixative and subsequent solutions in place of phosphate buffer. The fixed cultures were washed with phosphate- or Hepes-buffered saline, permeabilized with $0.05 \%$ saponin, and "blocked" with $0.1 \mathrm{M}$ glycine and $10 \%$ normal goat serum before labeling of neurites with the following antibodies (in the presence of $0.05 \%$ saponin): mouse monoclonal antibodies against MAP2 (4 $\mu \mathrm{g} / \mathrm{ml}$, Boehringer Mannheim), synaptophysin $(0.5 \mu \mathrm{g} / \mathrm{ml}$, Boehringer Mannheim), a phosphorylated epitope of neurofilament $\mathrm{H}$ (SMI-31 1:10,000, Sternherger Monoclonals), and/or rabhit polypeptide-specific antisera $R 9(1: 1000)$ and $R 14(1: 1600)$, recognizing the medium- and high-molecular weight neurofilament subunits, respectively (generously provided by Dr. Gerry Shaw, University of Florida Brain Institute, Gainesville, FL). The specificities of these antibodies have been previously described (Sternberger and Sternberger, 1983; Caceres et al., 1984; Wiedenmann and Franke, 1985; Harris et al., 1991). The SMI-3I antibody against a phosphorylated epitope of neurofilament $\mathrm{H}$ also shows a reaction with an unspecified epitope in the nuclei of neurons and other cells in cultures and developing tissues (L. Sternberger, personal communication). After incubation for two hr at room temperature or overnight at $4^{\circ} \mathrm{C}$ with these primary antibodies. the cultures were washed and then incubated with one or two of the following secondary antibodies: FITC-conjugated goat anti-rabbit IgG (Miles Inc., Kankakee, IL), affinity purified FITC-conjugated goat anti-mouse IgG, affinity purified AMCA-conjugated goat anti-mouse IgG. or affinity purified AMCA-conjugated goat anti-rabbit IgG (Jackson ImmunoResearch Laboratories, Inc., West Grove, PA).

In some experiments, the distributions of cytoplasmic peripheral membrane proteins and laminin with respect to neurite-induced AChR aggregates were analyzed using membrane preparations of the substrateattached (ventral) surface of the myotubes. After labeling AChRs with TRITC-BTX and rinsing, membranes were prepared by shearing the cells with a stream of buffer as described (Pumplin, 1989). The coverslips, to which the ventral membranes remained attached. were immediately placed into $2 \%$ paraformaldehyde solution in the same buffer and fixed for $15 \mathrm{~min}$. After fixation, the membranes were labeled with monoclonal antibodies against the 4.3 and $58 \mathrm{kDa}$ postsynaptic proteins at 8 and $10 \mu \mathrm{g} / \mathrm{ml}$, respectively (generously provided by Dr. Stanley Froehner, University of North Carolina, Chapel Hill), or rabbit antiserum to laminin at a dilution of 1:1000 (Bethesda Research Laboratories, Inc., Gaithersburg, MD) followed by the appropriate secondary antibodies, as described above, except that saponin treatment was not required for labeling the cytoplasmic proteins. The specificities of these primary antibodies have been described previously (Froehner, 1984 Bloch and Froehner, 1987; Froehner et al., 1987). The BRL product profile reported that their antiserum against laminin was specific, based on enzyme-linked immunosorbant assays and immunoprecipitation against a variety of extracellular matrix proteins.

Photomicroscopy and quantitation. Cultures were examined and photographed with a Zeiss Axioplan microscope equipped for fluorescence microscopy with a $100 \mathrm{~W}$ mercury arc lamp, narrow-band filter sets suitable for unambiguous detection of AMCA, FITC and TRITC and $63 \times$ plan-apochromat and plan-neofluor, phase contrast objective lenses (Carl Zeiss Inc., Thornwood, NY). For observations of living, fluorescently labeled cultures, and for digital image acquisition. the microscope was also equipped with a Venus low-light video camera (Carl Zeiss Inc.) and a Hamamatsu C4880 cooled CCD camera (Hamamatsu Photonic Systems, Bridgewater, NJ). These cameras permitted imaging with incident illumination reduced to $0.18 \%$ of maximum by neutral density filters in order to prevent damage to living cultures prior to fixation for electron microscopy.

For quantitation of the time course and cell type specificity of neurite contact-induced aggregation, fields with neurites (identified by neurofilament labeling) crossing the ventral surface of a myotube were randomly chosen. The percent of the neurite length crossing the myotube and associated with characteristic neurite-induced AChR aggregates was calculated from measurements of digitized images. Unless otherwise stated, at least 20 myotube fields from two sister cultures were analyzed and each experiment was repeated at least two times. The values reported were obtained by calculating the percent of neurite length associated with aggregates in each field and averaging the values for all fields. Virtually identical results were obtained by dividing the length associated with aggregates in all fields by the total neurite length mea- 
sured. Thus, variations in the lengths of neurites measured had little effect on the results. The quantitation of the relative capacity of axons and dendrites to induce AChR aggregation was carried out similarly. Cultures were selected by neurofilament labeling with polyclonal antibodies that were not generally selective for axons or dendrites. The neurite length that was neurofilament-positive but MAP2-weak or -negative was considered axonal. The neurite length that was clearly MAP2positive and had the morpholological characteristics of dendrites was considered dendritic, whether or not it was labeled with neurofilament antibodies. The distribution of AChRs in a field was not observed or recorded until axon and dendrite lengths had been established. In order to resolve certain ambiguities in the interpretation of results obtained by this assay, cocultures plated with only 4000 VSC cells/coverslip were labeled as described above, and individual neurons were selected for evaluation if they filled all of the following criteria: (1) some part of a neurite was associated with induced AChR aggregation, (2) both axons and dendrites of the neuron were in contact with a myotube, and (3) axons and dendrites could be traced with no evidence of direct contact or fasciculation with another neurite. In this case, the entire extent of individual neuron-myotube contacts were assayed, regardless of which surface of the myotube was involved.

Electron microscopy. For electron microscopic examination of neurite-muscle contacts with induced AChR aggregation, the contacts were first identified in living cultures by one of two strategies. (1) Characteristic AChR aggregates were identified by TRITC-BTX labeling and associated neurites were visualized by phase contrast microscopy, if possible. (2) Characteristic AChR aggregates were identified and bouton-like portions of neurites, presumed to be enriched in synaptic vesicles, were identified by activity dependent labeling with the dye FM143 (Molecular Probes, Inc.) essentially as described (Ryan et al., 1993). Briefly, the cultures were rinsed with a solution containing $120 \mathrm{~mm}$ $\mathrm{NaCl}, 2 \mathrm{mM} \mathrm{KCl}, 2 \mathrm{mM} \mathrm{CaCl}, 2 \mathrm{mM} \mathrm{MgCl}, 30 \mathrm{~mm}$ glucose, and 25 mM Hepes ( $\mathrm{pH} 7.4$ ), incubated with 8-12 $\mu \mathrm{M}$ FM1-43 in the same medium, but containing $90 \mathrm{mM} \mathrm{KCl}$ and $32 \mathrm{~mm} \mathrm{NaCl}$, for $1-5$ min to induce synaptic vesicle exocytosis and plasma membrane recycling, and then washed with the first solution three times in $5 \mathrm{~min}$ to remove dye that was not internalized. FM1-43 labeling was viewed with the FITC filter set. For observation, the coverslips were temporarily mounted on a chamber (containing Med-A) made with a glass slide and a perforated silicone rubber sheet coated with silicone grease. Identified regions were photographed and marked on the back of the coverslip with a Leitz diamond-tipped "objective" (Bunton Instrument Co., Rockville, MD). Cultures were fixed, osmicated, en bloc stained and embedded as described previously (Olek et al., 1986) with one of the following modifications in the initial fixation: Med-A was replaced gradually with a fixative consisting of $2.5 \%$ glutaraldehyde in $0.12 \mathrm{M}$ sodium cacodylate buffer ( $\mathrm{pH}$ 7.3). After $15 \mathrm{~min}$, this fixative was replaced by the same fixative solution with the addition of $0.15 \%$ tannic acid (to enhance the contrast of ECM and cytoskeletal structures). In a further modification that appeared to improve the quality of preservation of the neurites, growth cones, and "boutons," $0.1 \mathrm{~m}$ sucrose was added to the fixation buffer and the tannic acid concentration was reduced to $0.08 \%$. Marked regions were relocated in the embeddings and were sectioned transverse to the course of the neurites. Thin sections were stained with uranyl acetate and lead citrate and were viewed with a JEM 1200EXII electron microscope (JEOL US Inc., Peabody, MA).

\section{Results}

Redistribution of AChRs on myotubes induced by ventral spinal cord neurons

In order to investigate the early stages of neuromuscular synapse formation, we developed a mammalian coculture system using myotube cultures with relatively few nonmuscle cells. Typically, primary rat myotube cultures have an abundance of nonmuscle cells, largely fibroblasts, that cover much of the myotube surface (for example, see Olek et al., 1986). By using a selective replating procedure (Daniels, 1990), we were able to produce cultures containing large, flat, multipolar myotubes with relatively few fibroblasts and other nonmuscle cells and thus myotubes with extensive accessible surfaces (Daniels, 1990; Melton et al., 1993). Cells from the ventral part of the spinal cord (VSC), which is enriched in motor neurons, were plated on such cultures

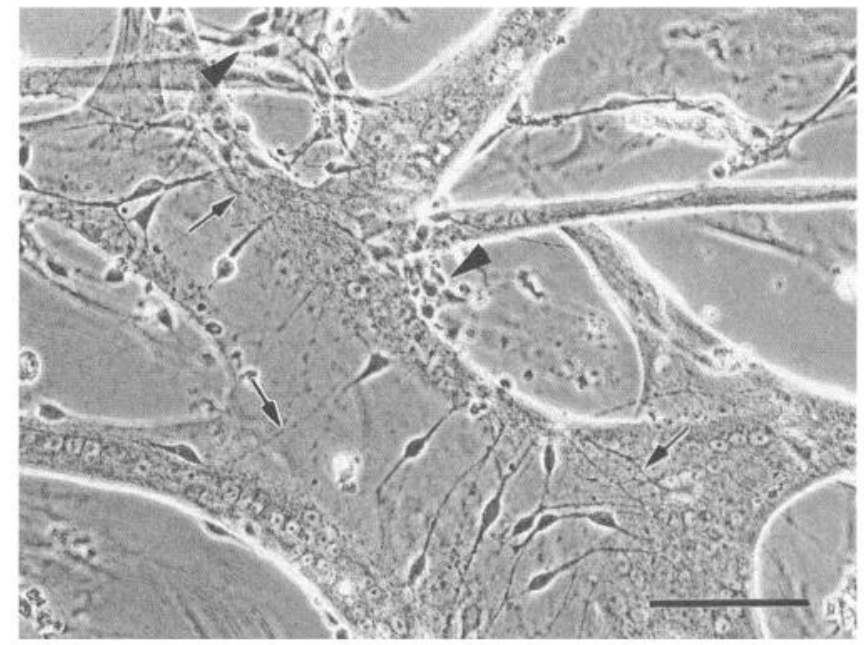

Figure 1. A VSC neuron-myotube coculture fixed $46 \mathrm{hr}$ after adding neurons. A large, multipolar myotube, filling most of the field, is contacted by many neuronal somata, which extend neurites (examples indicated by arrows) over the myotube surface. Some neurons are attached to the nonmuscle cells (arrowheads) and extend neurites over the substrate and the myotube surface. Scale bar, $100 \mu \mathrm{m}$.

2-3 d after the myoblasts fused to form myotubes. VSC cells adhered to the myotubes, in some cases even relocating beneath the myotubes, and also adhered to the substrate or nonmuscle cells between myotubes (Fig. 1). As early as $3 \mathrm{hr}$ after plating VSC cells on myotubes, small neurite extensions could be seen, and by $12 \mathrm{hr}$ substantial neurite outgrowth had occurred. Thin neurites often were difficult to detect by phase contrast microscopy, particularly when they passed beneath the myotubes, but were clearly visualized by immunofluorescent labeling with antibodies against neurofilament subunits or other proteins that are enriched in neurites.

One of the first changes in the postsynaptic membrane during neuromuscular junction formation is the accumulation of AChRs at the nerve-muscle contact site (Hall and Sanes, 1993). To determine if neurites in our coculture system had induced a redistribution of AChR, the receptors were labeled with TRITC-BTX and their distribution at neurite-myotube contact sites was examined. We found two distinct patterns of AChR redistribution at some of these sites. Rat myotube cultures contain AChR aggregates or "patches" that form on the substrate-apposed (ventral) surface of the myotubes (Axelrod et al., 1976). Where neurites crossed these preexisting patches, the relative AChR density on the muscle surface directly apposed to the neurite was sharply reduced, as if the neurite had "etched" the ventral receptor patch. The density within $1 \mu \mathrm{m}$ from the neurite, however, often appeared higher than that of the surrounding ventral receptor patch (Fig. 2C). Secondly, we observed an accumulation of AChR in 5-10 $\mu \mathrm{m}$ wide swaths along the paths of some neurites. The continuous lengths of neurites associated with newly induced AChR aggregates varied from as little as $10 \mu \mathrm{m}$ to greater than $100 \mu \mathrm{m}$. As seen with "etched" ventral patches, the relative $A C h R$ density in the narrow region of the newly induced aggregates directly apposed to the neurite was usually reduced (Fig. 2D). Ventral-etched and newly induced AChR aggregates could both be found in association with a single neurite (Fig. 2E).

Induction of AChR redistribution by neurite contact occurred predominantly on the ventral surface of myotubes, but newly 

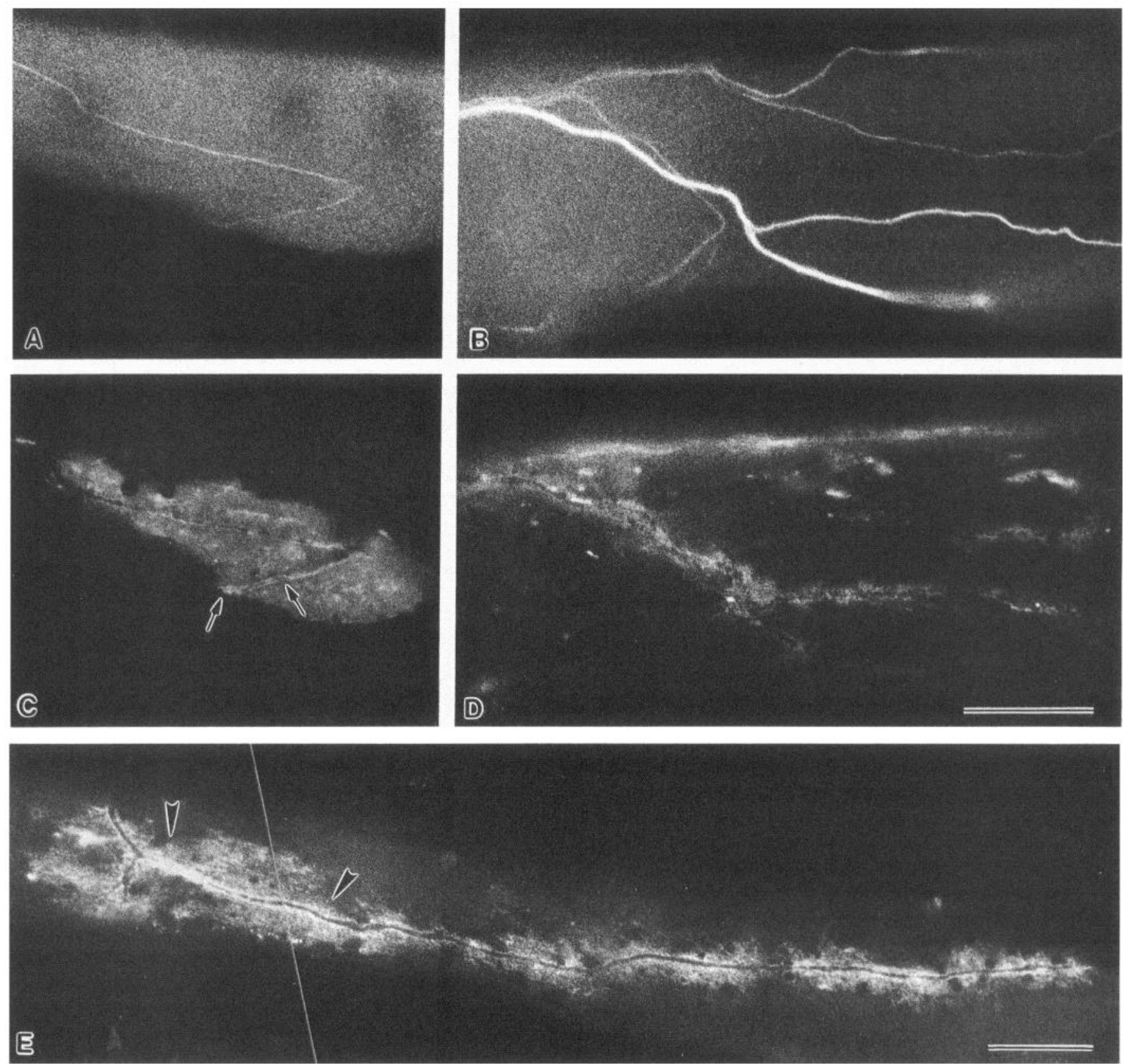

Figure 2. Redistribution of AChRs on the ventral surface of myotubes induced by neurite contact. $A$ and $B$ show neurites delineated by neurofilament protein immunoreactivity. $C$ and $D$ show the distribution of AChRs (TRITC-BTX labeling) in the same fields as $A$ and $B$, respectively; $E$ shows AChR distribution in another field. In $A$ and $C$, a neurite has crossed a typical ventral receptor patch and made a sharp turn within the patch. $\mathrm{AChR}$ density is reduced ("etched") along most of the neurite's path but is increased in a very narrow band on either side of the neurite (arrows). In $B$ and $D$, neurites are associated with swaths of newly aggregated AChRs. In $E$, a neurite path is associated with newly induced AChR aggregation as well as "etching" of a ventral receptor patch (between arrowheads). Scale bars, $20 \mu \mathrm{m}$.

induced AChR aggregates of similar appearance could be found on the "dorsal" surface, as well, particularly in cultures with higher than usual numbers of nonmuscle cells. In addition, we observed oval-shaped AChR aggregates on the dorsal surface of myotubes (data not shown) resembling those induced by embryonic brain extract or neuronal conditioned medium (see, for example, Daniels, 1990).

Both patterns of neurite-induced AChR redistribution were observed as early as six hr after VSC cell plating, with newly induced $\mathrm{AChR}$ aggregation reaching a maximum between 36 and $48 \mathrm{hr}$ after plating (Fig. 3). From 6-48 hr there was an increase in the percentage of neurite length associated with newly induced $\mathrm{AChR}$ aggregates and an increase in the frequency of fields in which such interaction had occurred. Newly induced AChR aggregates were abundant for up to $7 \mathrm{~d}$ after VSC cell plating (the latest time examined) but were not assayed quantitatively after $48 \mathrm{hr}$.

It has been reported that AChR accumulation at sites of synapse formation is due in part to redistribution of preexisting surface receptors and in part to the preferential insertion of new- 


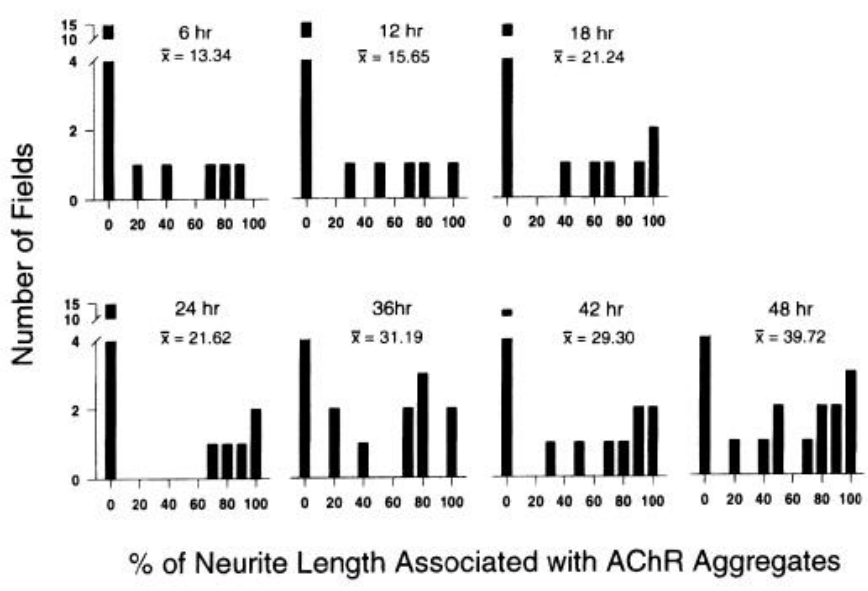

Figure 3. Time course of neurite-induced AChR aggregation in VSCmyotube cocultures. At each time point, cocultures were labeled with RITC-BTX for AChRs, fixed and labeled for neurofilaments (see Materials and Methods). Neurite-induced AChR aggregation was assayed in 20 fields for each time point as described in Materials and Methods. Maximal aggregation occurred between 36 and $48 \mathrm{hr}$. The histograms show non-normal distributions; thus, SEMs are not given.

ly synthesized receptors (Anderson et al., 1977; Ziskind-Conhaim et al., 1984; Role et al., 1985). To determine whether the pattern of AChR aggregation seen in the present system involved a redistribution of preexisting receptors, AChRs were labeled prior to the addition of neurons to myotube cultures. We found essentially the same pattern of newly induced AChR aggregation and ventral-etched patches with prelabeled AChR as with labeling just prior to fixation (Fig. 4). This indicates that the newly induced AChR aggregation that we observe in this system is due at least in part to a redistribution of preexisting AChRs, and further indicates that the low density of AChRs detected directly over the course of the neurite is not the result of any barrier for TRITC-BTX access to those sites.

\section{Cell-type specificity of neurite-induced AChR redistribution}

In Xenopus and chick cultures, neurons from the spinal cord or ciliary ganglion (many of which are motor neurons) have a much greater capacity for neurite contact-induced AChR aggregation in culture than neurons from tissues lacking motor neurons (Cohen and Weldon, 1980; Role et al., 1985), suggesting that the functional expression of one or more signaling molecules needed for this induction might be specific to motor neurons. In order to test this hypothesis further, we plated cells from the superior cervical ganglion (SCG), dorsal root ganglion (DRG), hippocampus and VSC on myotubes and compared the frequency of neurite-myotube contacts associated with newly induced aggregates (those with the characteristic morphology described above) and the percent of neurite length in contact with myotubes that was associated with newly induced $\mathrm{AChR}$ aggregates. In VSC-myotube cultures, approximately $48 \%$ of fields containing neurites in contact with myotubes were associated with newly induced AChR aggregates after 24 or $48 \mathrm{hr}$, as compared to approximately $27 \%, 25 \%$, and $24 \%$ for SCG, DRG, and hippocampal neurons, respectively (mean of 24 and $48 \mathrm{hr}$ values; Table 1). Approximately $30 \%$ of the length of VSC neurites in contact with myotubes was associated with newly induced AChR aggregates after 24 or $48 \mathrm{hr}$, as compared to approximately $11 \%, 10 \%$, and $12 \%$ for SCG, DRG, and hippocampal. neurites, respectively (Table 1). Thus, AChR aggre-
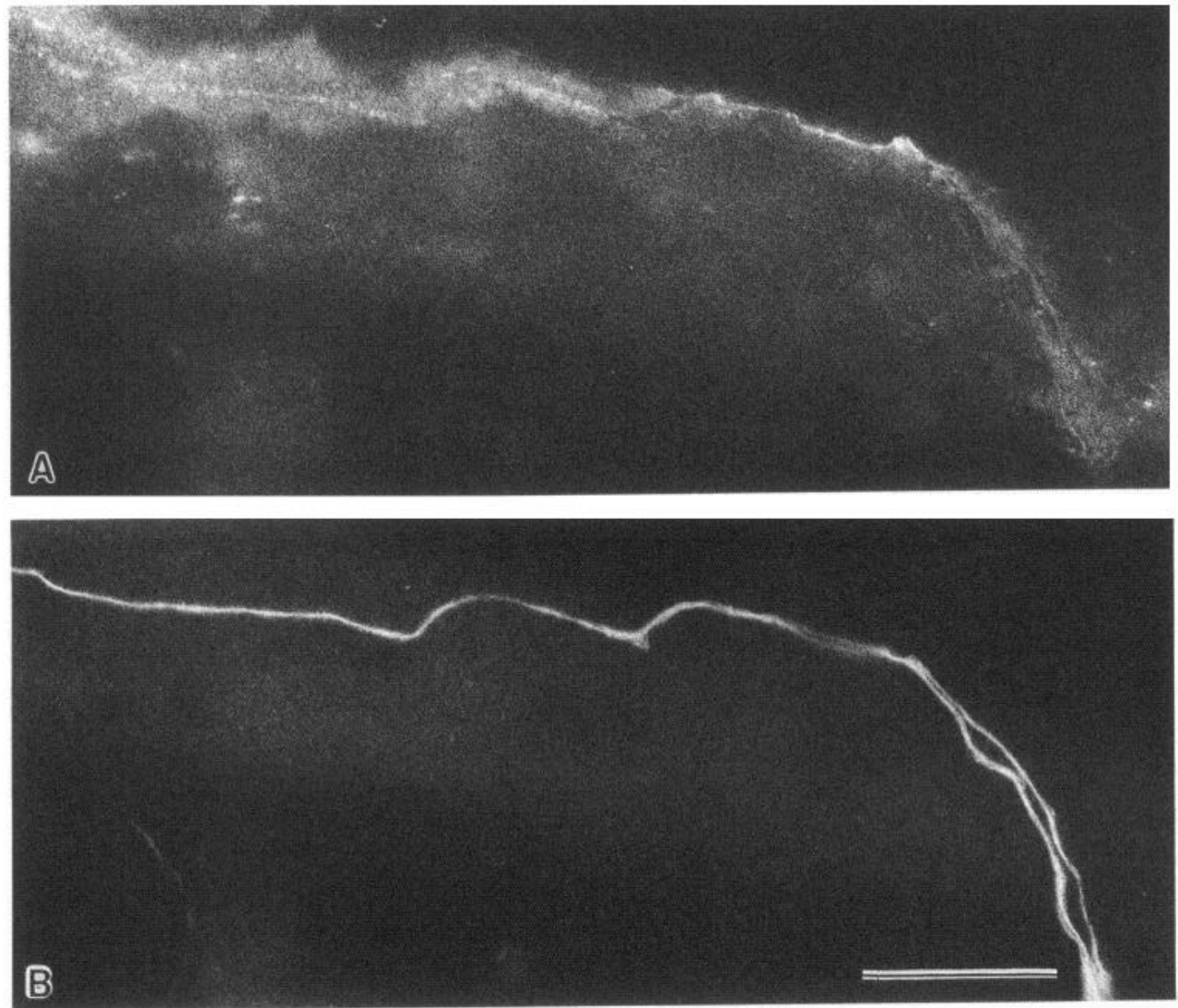

Figure 4. Newly induced $\mathrm{AChR}$ aggregation $(A)$ along the course of a neurite $(B)$ in a coculture that was labeled with TRITC-BTX prior to the addition of neurons to the myotube culture and fixed $19 \mathrm{hr}$ later. The AChR distribution seen here represents receptors that were present on the myotube surface prior to any innervation. It is similar to the distribution of newly aggregated receptors observed with TRITC-BTX labeling just prior to fixation. Scale bar, $20 \mu \mathrm{m}$. 


\begin{tabular}{|c|c|c|}
\hline $\begin{array}{l}\text { Neuron } \\
\text { cell type }\end{array}$ & $\begin{array}{l}\% \text { Neurite/myotube } \\
\text { contact fields with } \\
\text { aggregates }^{b}\end{array}$ & $\begin{array}{l}\% \text { Neurite length } \\
\text { with aggregates }\end{array}$ \\
\hline \multicolumn{3}{|c|}{$\operatorname{VSC}(n=120)$} \\
\hline $24 \mathrm{hr}$ & $47.0(35-60)$ & $29.8(20.4-40.4)$ \\
\hline $48 \mathrm{hr}$ & $49.1(35-75)$ & $29.3(23.1-40.7)$ \\
\hline \multicolumn{3}{|c|}{ Hipp $(n=40)$} \\
\hline $24 \mathrm{hr}$ & $15.0(15,15)$ & $8.1(8.6,7.6)$ \\
\hline $48 \mathrm{hr}$ & $32.5(30,35)$ & $13.9(10.3,17.5)$ \\
\hline \multicolumn{3}{|c|}{ SCG $(n=40)$} \\
\hline $24 \mathrm{hr}$ & $32.5(15,50)$ & $11.7(19.2,4.3)$ \\
\hline $48 \mathrm{hr}$ & $25.0(20,30)$ & $10.5(16.7,4.4)$ \\
\hline \multicolumn{3}{|c|}{ DRG $(n=40)$} \\
\hline $24 \mathrm{hr}$ & $30.0(25,35)$ & $8.9(7.5,10.3)$ \\
\hline $48 \mathrm{hr}$ & $20.0(15,25)$ & $10.7(14.7,6.4)$ \\
\hline
\end{tabular}

"The $n$ values are the number of fields examined at each time point.

${ }^{b}$ Values given are the means from two experiments in the case of hippocampus, SCG, and DRG, and six experiments in the case of VSC (see Materials and Methods), with the range of values from different experiments given in parentheses.

gation was most strongly elicited by contact with VSC neurites, but neurons from the other sources showed significant activity.

\section{Association of the $43 \mathrm{kDa}$ and $58 \mathrm{kDa}$ proteins and laminin with the myotube membrane at neurite-induced AChR aggregation sites}

It has been shown that specific peripheral membrane proteins (Froehner, 1993) and basal lamina components (Anderson and Fambrough, 1983; Chiu and Sanes, 1984; Godfrey et al., 1988) are concentrated at developing NMJs in vivo and in vitro. As part of the characterization of newly induced aggregation sites, we examined the distribution of two cytoplasmic proteins that are associated with the postsynaptic membrane at the neuromuscular junction, and laminin, the major glycoprotein of the basal lamina. Preparations of substrate-attached (ventral cell surface) membranes were labeled with antibodies to the $43 \mathrm{kDa}$ and $58 \mathrm{kDa}$ (syntrophin; Adams et al., 1993) proteins. These proteins were always concentrated in AChR-enriched domains within newly induced $\mathrm{AChR}$ aggregates and were reduced in concentration where neurites had "etched" preexisting aggregates (Fig. 5). Laminin also was concentrated over AChR-enriched domains in some newly induced aggregates, but was weakly associated with these domains in other aggregates (Fig. 6 ), suggesting the possibility that basal lamina formation at these sites may lag behind reorganization of the myotube membrane.

\section{Fine structure at sites of newly induced AChR aggregation}

The observation that postsynaptic proteins and a major basal lamina component, laminin, were concentrated at newly induced AChR aggregates in addition to the observation of immunoreactivity for the synaptic vesicle protein, synaptophysin (described below), suggested the presence of both pre- and postsynaptic structural specializations at the sites of newly induced AChR aggregation. To investigate this, we located and photographed (or digitally recorded) regions showing newly induced AChR aggregation, then prepared cultures for thin-section transmission electron microscopy. In $48 \mathrm{hr}$ cocultures (Fig. 7), the
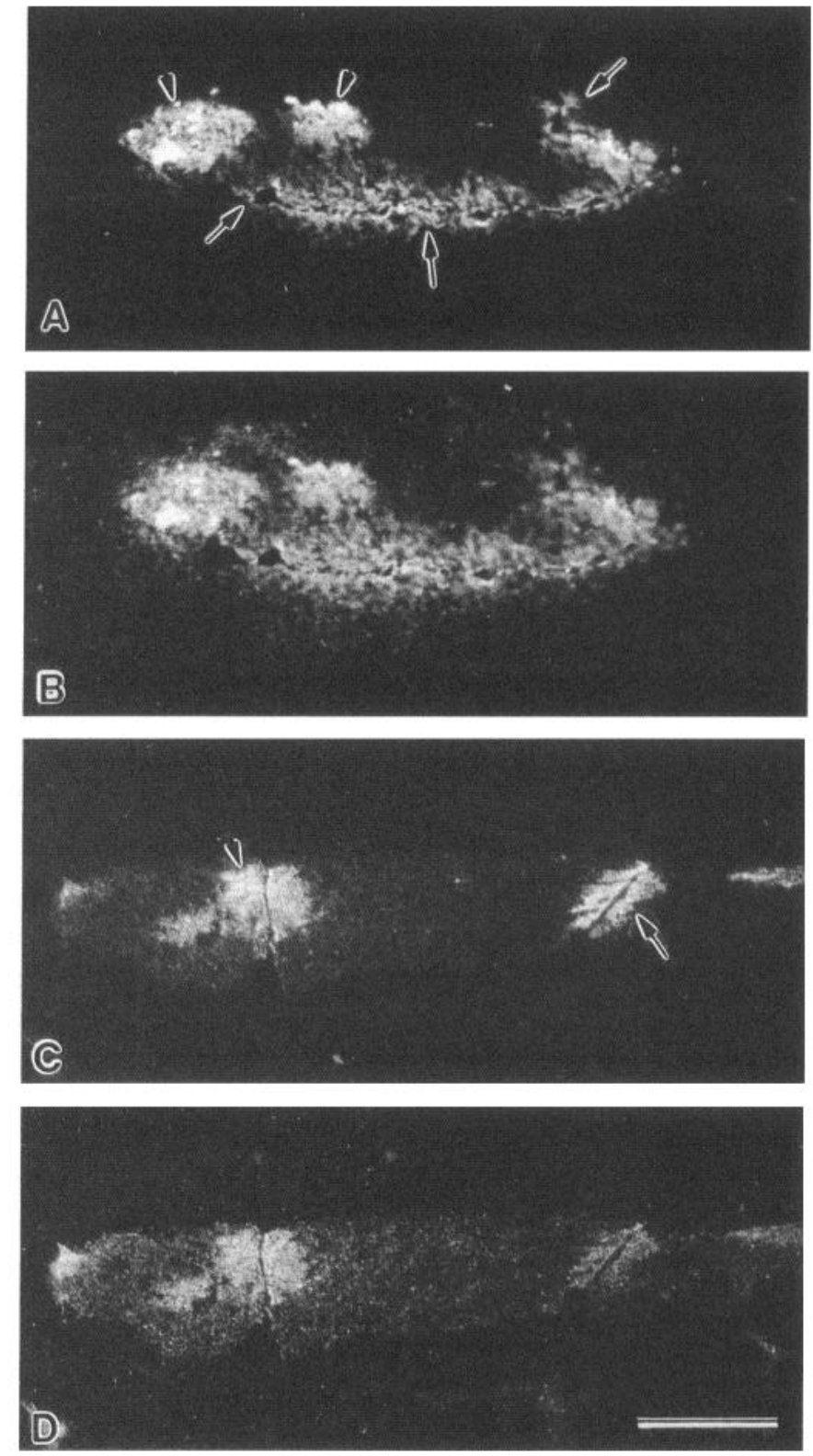

Figure 5. Colocalization of immunoreactivity for $43 \mathrm{kDa}$ protein $(B)$ and syntrophin $(D)$ with newly aggregated AChRs (arrows, $A$ and $C$ ) in substrate-attached (ventral cell-surface) membranes prepared by shearing away the remainder of the cell. Small preexisting AChR patches in $A$ and $C$ are indicated with arrowheads. The preexisting patch in $C$ was "etched" by a neurite. Scale bar, $20 \mu \mathrm{m}$.

most striking feature found in these regions was a dense submembrane specialization that was sometimes associated with basal lamina. These cell surface specializations appeared to be coextensive with receptor-enriched domains, as they were found immediately lateral to the site of neurite-muscle contact, but not within the contact site itself. The contact site was characterized by close apposition of the neurite and myotube plasma membranes and a gutter-like infolding of the myotube surface that partially, or in some cases completely, enfolded the neurite. Formation of a myotube gutter around the neurite was observed even when the surrounding regions of the myotube were not closely apposed to the substrate, suggesting that it was the result of adhesion between the neurite and the muscle cell surface. The 

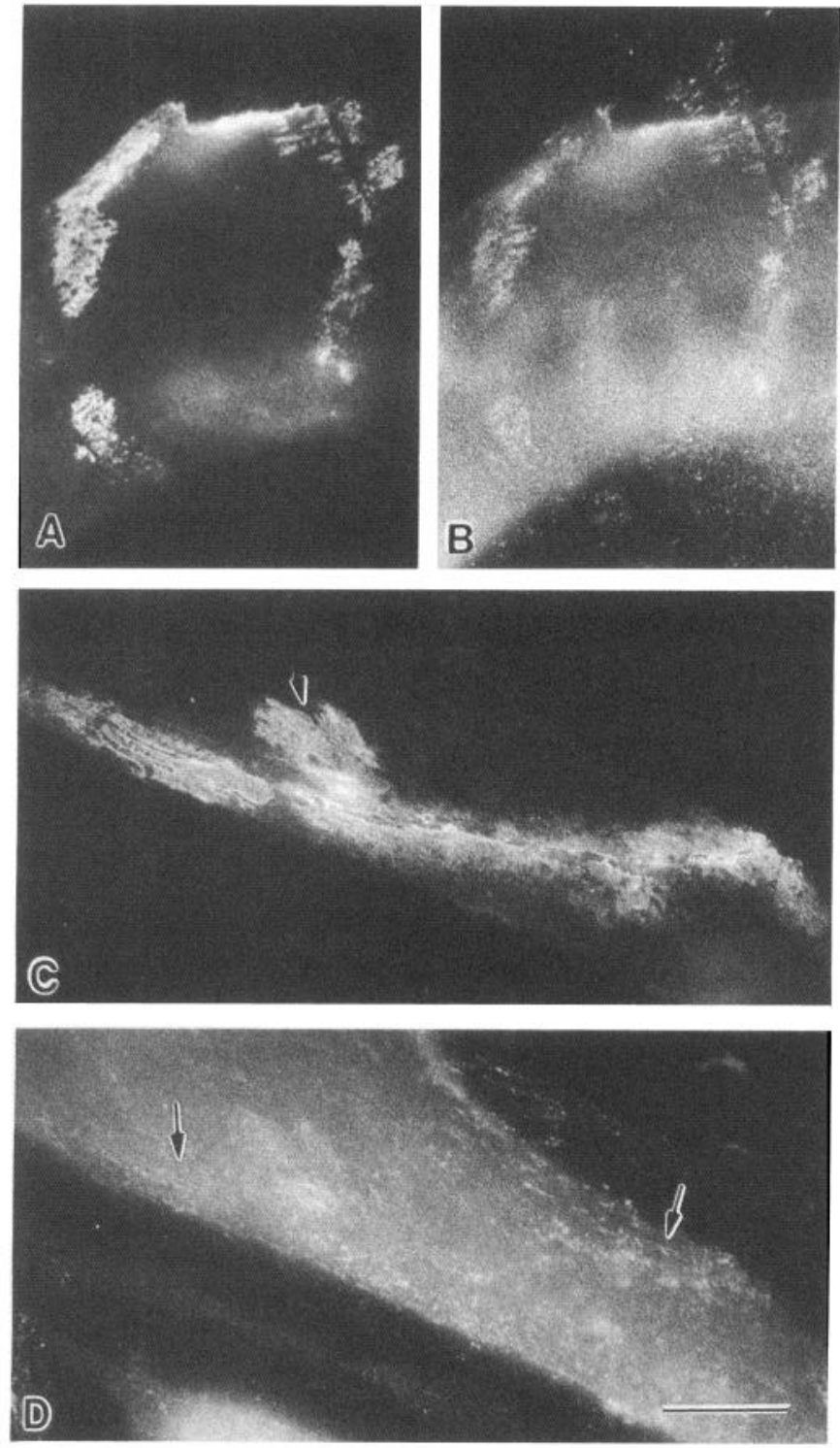

Figure 6. Variable colocalization of immunoreactivity for laminin (B, $D$ ) with newly aggregated $\mathrm{AChRs}(A, C)$. In some instances, the distribution of laminin corresponds closely to AChR-enriched domains $(A$, $B$ ), while in others, there are only sparse deposits of laminin (arrows) associated with the aggregates $(C, D)$. Arrowhead in $C$ indicates a small ventral receptor patch. Scale bar, $20 \mu \mathrm{m}$.

neurites displayed an array of organelles typical of developing axons (Grainger et al., 1968; Lyser, 1968), including a core of microtubules, mitochondria, and irregular membrane profiles. Neurite segments often displayed lateral extensions resembling filopodia or lamellipodia and clusters of large, irregular vesicles resembling those found in growth cones (see, for example, Rees et al., 1976). In agreement with the finely punctate appearance of synaptophysin immunoreactivity observed in these cultures, clear and dense-core synaptic vesicles were usually found in a sparse distribution along the neurites; clusters of clear synaptic vesicles were observed occasionally (data not shown).

Older cocultures labeled with antibodies to synaptophysin showed bouton-like immunoreactivity at neurite-myotube contacts (described below) that was suggestive of the accumulation of synaptic vesicles and the possibility of a more general syn- aptic maturation. To look further for signs of this maturation, we labeled 6 or $7 \mathrm{~d}$ old cocultures with TRITC-BTX and then with FM1-43, under conditions where the uptake of this dye should be enhanced by synaptic vesicle recycling (Betz et al., 1992). We located and made detailed electron microscopic observations of two regions that contained bouton-like accumulations of FM1-43 in neurites associated with induced AChR aggregates. In sites corresponding to the location of the "boutons," we indeed found evidence of synaptic maturation (Fig. 8). There were expansions from the central core of the neurites that contained clusters of clear synaptic vesicles as well as dense-core vesicles. The vesicle clusters were usually close to the plasma membrane and, in some regions, there were dense structures between the membrane and the vesicles that resembled those found at active zones in developing NMJs (Weldon and Cohen, 1979; Nakajima et al., 1980). Whereas in the earlier junctions, sarcolemmal specializations tended to occur immediately lateral to the nerve-muscle contact site, in the older junctions sarcolemmal specializations often faced the presynaptic membrane. In addition, the gap between the expanded portion of the neurite and the myotube, although irregular, was generally larger than gaps found in the younger cocultures and this separation was related to the appearance of a basal lamina, as in maturing NMJs (Kelly and Zacks, 1969). In addition to the gutter found in the contact sites in younger cultures, extensive infolding of the myotube plasma membrane was observed. Unlike the mature NMJ, however, submembrane specializations were found in the depths of these folds as well as in the regions close to the axon.

\section{Axonal specificity of contact-induced AChR aggregation}

Spinal motor neurons in vivo extend an elaborate dendritic tree within the spinal cord, but only the axons emerge from the cord to innervate skeletal muscle. In order to determine whether the ability to induce AChR aggregation at sites of contact with skeletal muscle is a specific property of axons, we examined axonal and dendritic properties of VSC cell neurites in 2-6 d old cocultures and compared the ability of axon- and dendrite-like neurites to induce $\mathrm{AChR}$ aggregation. Immunofluorescent labeling of cocultures with monoclonal antibodies recognizing two proteins known to be concentrated in axons (Craig and Banker, 1994), synaptophysin (Wiedenmann and Franke, 1985) and the phosphorylated neurofilament heavy subunit (NF-H; Sternberger and Sternberger, 1983), revealed a population of long, thin neurites (Fig. 9) that were often difficult or impossible to see by phase contrast microscopy. These neurites could also be visualized with polyclonal antibodies against neurofilaments. While the labeling for phosphorylated NF-H was generally smooth and linear, synaptophysin labeling had a punctate appearance, which became coarser as the cultures matured, as expected for a synaptic vesicle protein (Figs. 9, 11). These antibodies rarely labeled neuronal somata or the dendrite-like processes. Somata and dendrite-like processes were revealed by phase contrast microscopy, by polyclonal neurofilament antibodies and, most efficiently, by labeling with a monoclonal antibody against the high molecular weight microtubule-associated protein, MAP2. As reported previously for cerebellar (Matus et al., 1981) and other neurons in vivo (Tucker, 1990), and for hippocampal and other brain neurons in culture (Tucker, 1990; Craig and Banker, 1994), MAP2 was concentrated in all neuronal somata, and in the thick, tapering dendrite-like processes that extended relatively short distances from the somata and often displayed irregular contours and fine branches (Fig. 10). In the present 

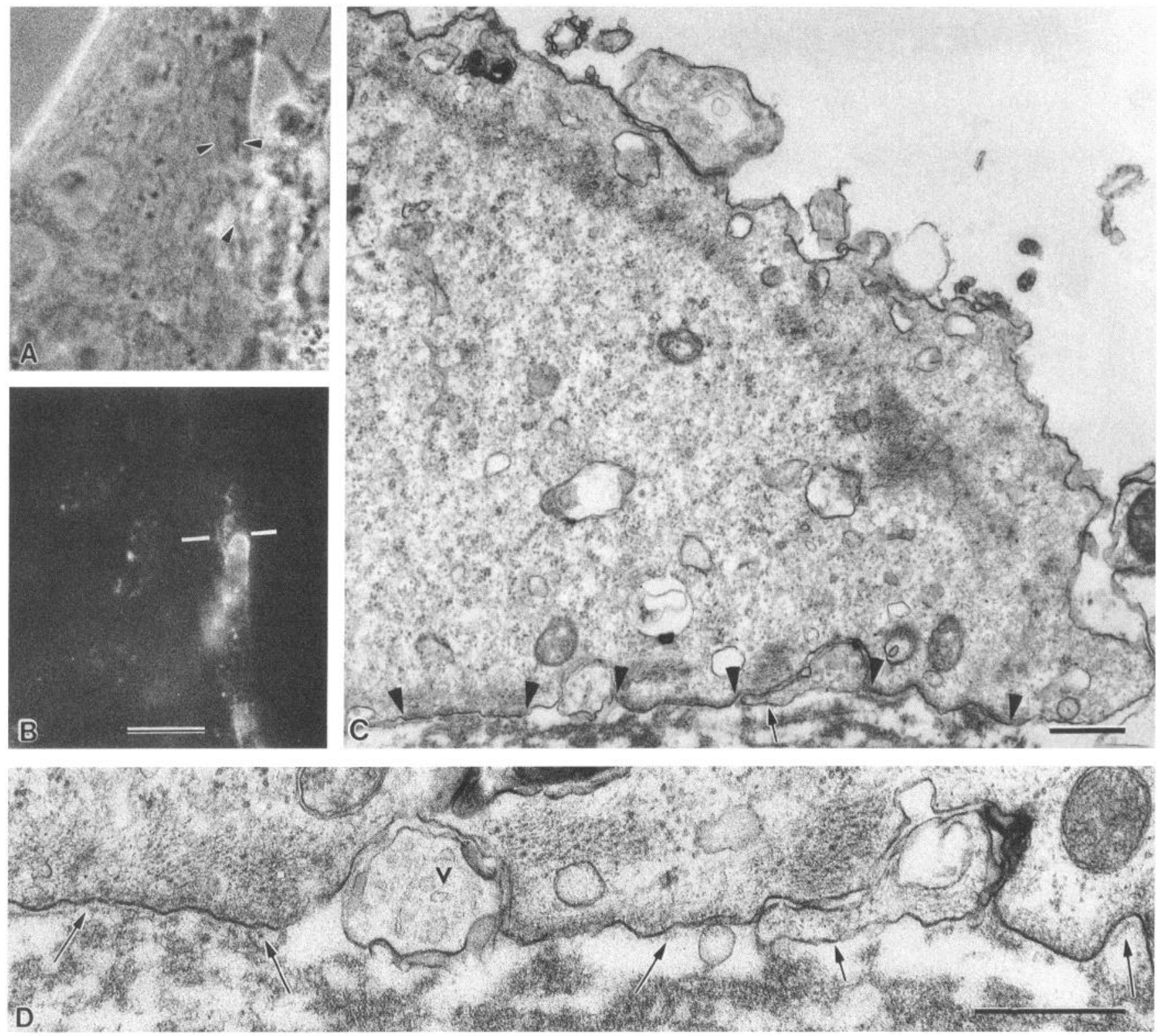

Figure 7. Ultrastructural specializations at a site of neurite-induced AChR aggregation in a $2 \mathrm{~d}$ old coculture. A branching neurite (arrowheads in $A)$ is associated with accumulations of AChRs $(B)$ on the ventral surface of a myotube. Electron micrographs $(C$ and a serial section at higher magnification in $D$ ) show transverse sections taken at the level indicated by the lines in $B$. The neurites are partially enclosed by gutters on the myotube surface corresponding to regions of reduced AChR density within the newly induced aggregate, and are in close contact with that surface. The dense membranous whorl seen at one neurite-myotube interface (right-hand contact in $D$ ) is probably a fixation artifact resulting from the protocol used in this example (see Materials and Methods). The neurites contain scattered small vesicles $(v)$ and a process resembling a lamellipodium extends from one of the neurites (short arrow). The myotube shows dense sarcolemmal specializations (between pairs of large arrowheads in C) in the regions of increased $\mathrm{AChR}$ density adjacent to the gutters, but not within the region of close contact with the neurites. The specialized regions of the sarcolemma are partially associated with basal lamina (long arrows, D). Scale bars: $10 \mu \mathrm{m}$ (photomicrographs) and $1 \mu \mathrm{m}$ (electron micrographs).

study, long, thin axon-like processes visualized by labeling with polyclonal neurofilament antibodies (henceforth referred to as axons) often displayed a weak immunoreactivity with the MAP2 monoclonal antibody, but were easily distinguished from the brightly labeled dendrite-like neurites (henceforth referred to as dendrites). The labeling of dendrites and somata with the polyclonal neurofilament antibodies was variable from cell to cell, even with the routine use of antibodies against NF-H and NF-M in combination.

We extensively examined cocultures labeled with TRITC-
BTX in combination with the monoclonal antibodies recognizing synaptophysin, phosphorylated NF-H and MAP2, sometimes in a triple-labeling combination with polyclonal NF antibodies. The results suggested that axons (Fig. 11) had a much greater ability to induce aggregation of AChRs than did dendrites. Since our interpretation could have been biased by the greater overall extension of axons than dendrites in the $48 \mathrm{hr}$ old cultures, a quantitative assay was performed on $48 \mathrm{hr}$ old cocultures that were simultaneously labeled with TRITC-BTX, the MAP2 monoclonal antibody, and the two polyclonal NF antibodies. For this 

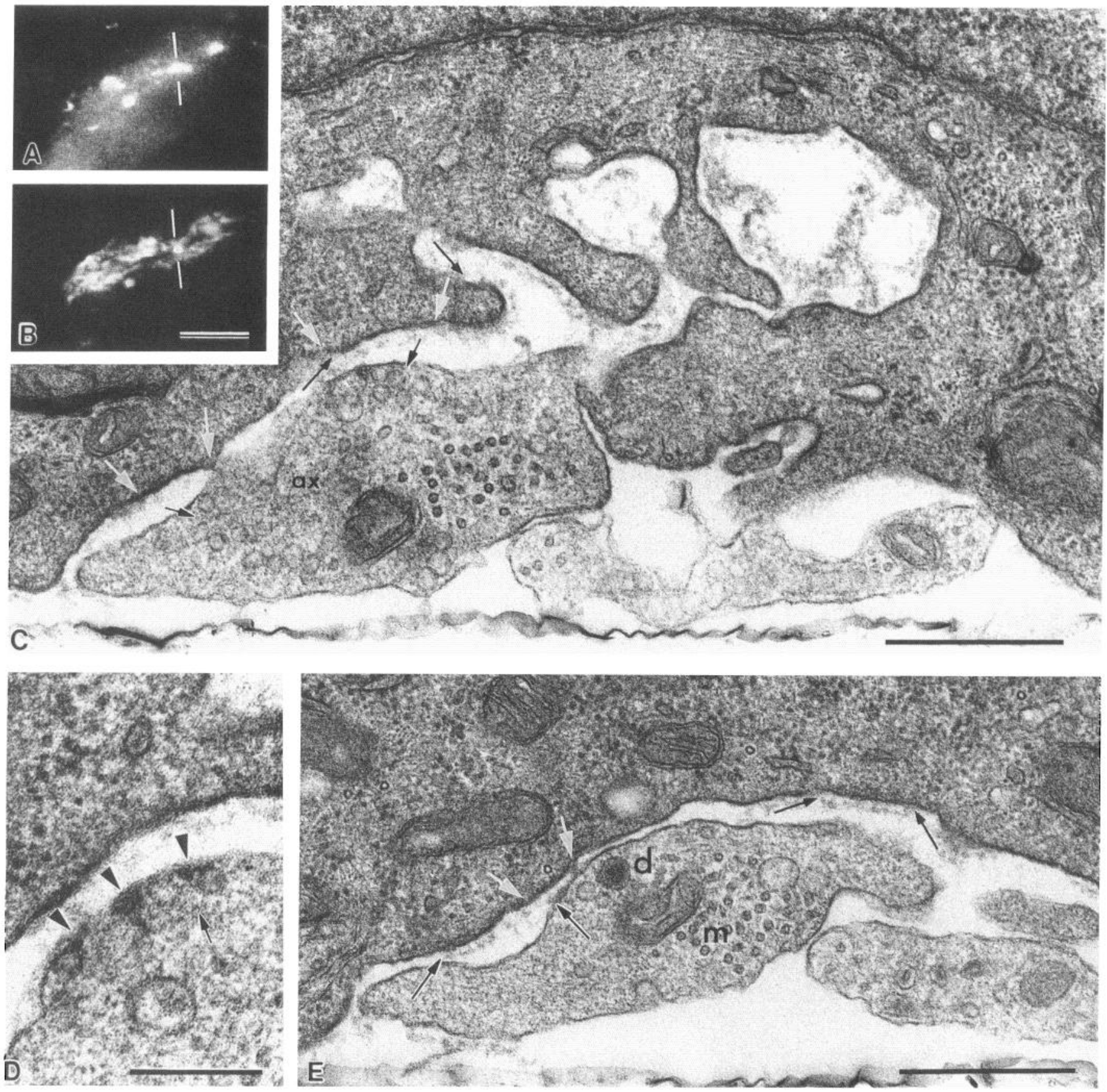

Figure 8. Synaptic structure at a neurite-induced AChR aggregate in a $6 \mathrm{~d}$ old coculture. Structures resembling boutons were identified by uptake of FM1-43 $(A)$ at a site of neurite-induced AChR aggregation $(B)$. The electron micrographs $(C-E)$ show transverse sections taken at the level indicated by the lines in $A$ and $B$. The bright, round spot seen between the lines in $B$ appeared to be an artifact, not corresponding to AChR concentration. The expanded neurite segments contain clusters of clear synaptic vesicles (short arrows) and some dense-core vesicles (d) as well as a bundle of microtubules $(\mathrm{m})$. The clear vesicles sometime cluster near the presynaptic membrane, close to dense structures resembling those found in active zones (arrowheads). The synaptic cleft is $50-100 \mathrm{~nm}$ wide in most places and contains a distinct basal lamina (examples shown between black arrows). Dense sarcolemmal specializations are found in the regions (between white arrows; $C, D$ ) facing clusters of vesicles and also in folded regions of the myotube surface $(C)$. Scale bars: $10 \mu \mathrm{m}$ (photomicrographs) and $0.5 \mu \mathrm{m}$ (electron micrographs).

assay, axons were defined as uniformly thin neurites that were brightly labeled with the NF antibodies but weakly labeled with the MAP2 antibody, if at all. Dendrites were defined as tapering neurites that were brightly labeled with the MAP2 antibody. These usually could be seen to extend a relatively short distance from a neuron soma in contact with the myotube. We found that $29 \%$ of the length of axons in contact with the ventral surface of myotubes was associated with characteristic AChR aggregates, while the value for dendrites was only $12 \%$ (Table 2A). Moreover, in performing this assay, we frequently noticed that dendrites were fasciculated with axons (for example, see Fig. 9). Evaluation of the tracings of neurites and newly induced AChR aggregates used to obtain the quantitative data showed that, of the $12 \%$ of the length of dendrites that was associated 

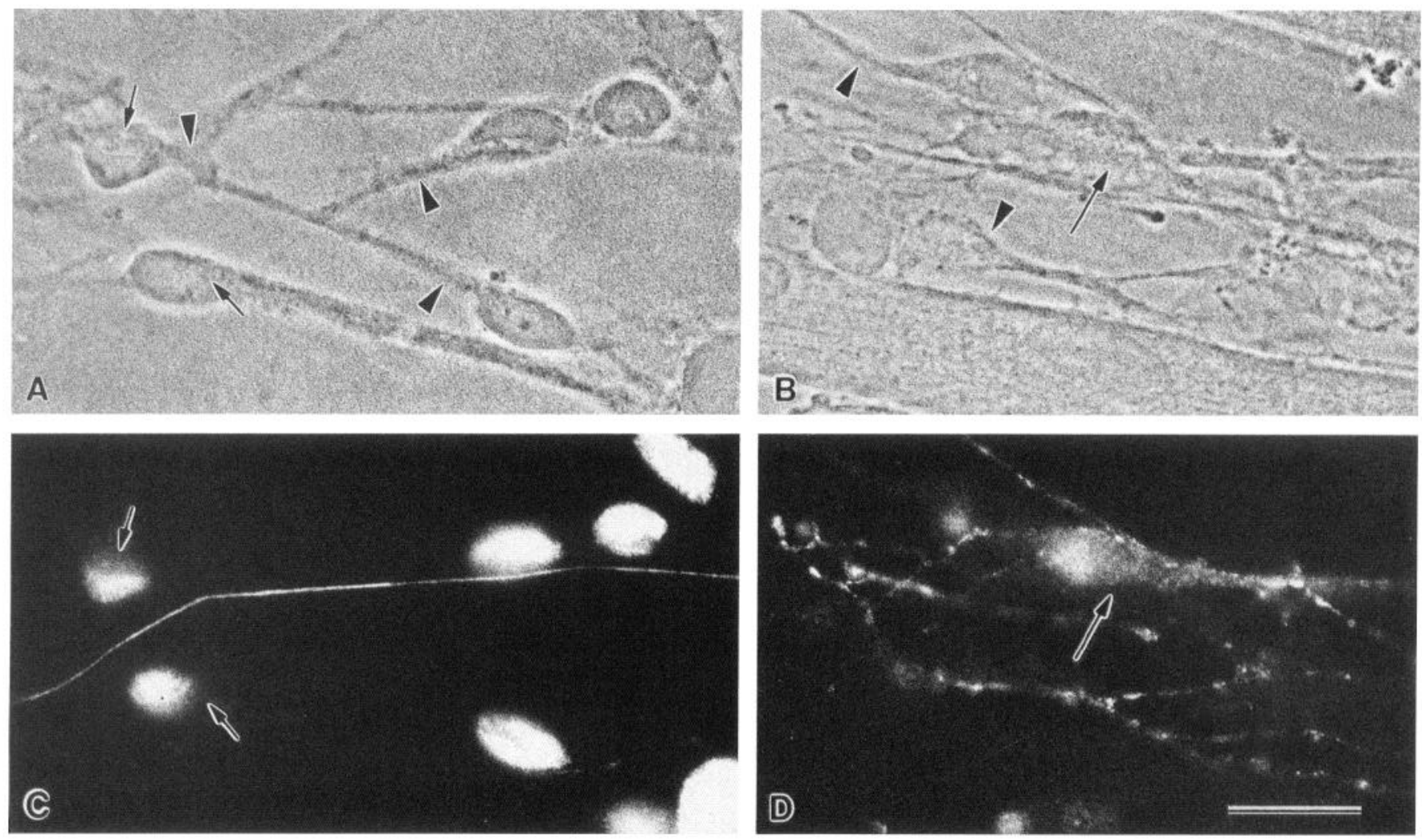

Figure 9. Labeling of axonal processes by antibodies against phosphorylated neurofilament $\mathrm{H}$ subunit (SMI-31) and synaptophysin in a 2 d old coculture. In $C$, SMI-31 labels a single fine axon traversing the field, while neuronal perikarya and dendrites seen by phase contrast $(A)$ are unlabeled. Note that this antibody also labels nuclei (see Materials and Methods). The brightness of nuclear labeling makes it difficult to distinguish from perikaryal labeling in these small neurons, but unlabeled perikarya can be clearly seen (short arrows in $A, C$ ). In $D$, synaptophysin antibodies label several axons in a punctate pattern, but only one neuronal perikaryon and dendrite are labeled (arrow). Examples of major neuronal processes that are unlabeled are indicated with arrowheads. Scale bar, $20 \mu \mathrm{m}$.

with AChR aggregates, $8 \%$ appeared to be fasciculated with axons that had extended beyond the dendrite to induce AChR aggregation whereas only $4 \%$ were apparently not fasciculated with such axons. On the basis of these results, we initially estimated that axons in these cocultures induced AChR aggregation approximately eight times more efficiently than did dendrites. Some questions remained in the interpretation of these results, first because of the fasciculation of neurites, and because it was possible that there were differences in the relative extent of axon and dendrite outgrowth in those neurons that induced AChR aggregation compared to those that did not. A modified assay was performed to eliminate these problems. For this assay, cultures were seeded with neurons at 4000 per coverslip, less than one-tenth the usual number. Under these conditions it was possible to find neurons in $2 \mathrm{~d}$ old cocultures that had induced AChR aggregation, had both axons and dendrites in contact with the myotube and could be traced unequivocally (Fig. 12). Ten out of 11 neurons fulfilling these criteria (nine coverslips) had induced aggregation along the axons, while only 4 of 11 had induced aggregation along dendrites. Approximately $27 \%$ of the length of axons but only $2.6 \%$ of the length of dendrites was associated with newly induced AChR aggregates (Table 2B), suggesting that dendrites of those neurons which induce $A C h R$ aggregation have less than one-tenth the capacity to do so than axons of the same neurons. It is interesting that about two-thirds of the dendrite-associated aggregation was found along dendrite segments proximal to sites from which axons emanated.

\section{Discussion}

We have found that plating dissociated VSC neurons on cultures of large myotubes that are essentially free of nonmuscle cells provides for extensive early contact between neurons and muscle, and extensive neurite-induced redistribution of AChR. The reason that earlier investigators failed to observe extensive redistribution in mammalian primary cell cocultures (Kidokoro et al., 1976; Kidokoro, 1980; discussed in Nakajima et al., 1980) remains unclear. However, the paucity of nonmuscle cells in our coculture system and in cultures of Xenopus myocytes supports the possibility that nonmuscle cells interfere with this interaction. This idea was also supported by our observations of cocultures in which the number of nonmuscle cells was higher and the extent of neurite-induced $\mathrm{AChR}$ redistribution was reduced (M. P. Daniels, S. J. Samuelsson, and C.-S. Uhm, unpublished observtions). Interference could result from the formation of a physical barrier by nonmuscle cells. Alternatively, it could be due to the deposition of ECM by nonmuscle cells such as fibroblasts, to their stimulation of ECM deposition by the myotubes (Sanderson et al., 1986) or to the release of other factors that might interfere with neurite-induced AChR aggregation. In this regard, it is noteworthy that only low levels of ECM are present in skeletal muscle in vivo at the initiation of $\mathrm{NMJ}$ formation (Kelly and Zacks, 1969; Chiu and Sanes, 1984).

Spatial and temporal pattern of AChR redistribution. We observed two distinct patterns of AChR redistribution: local re- 

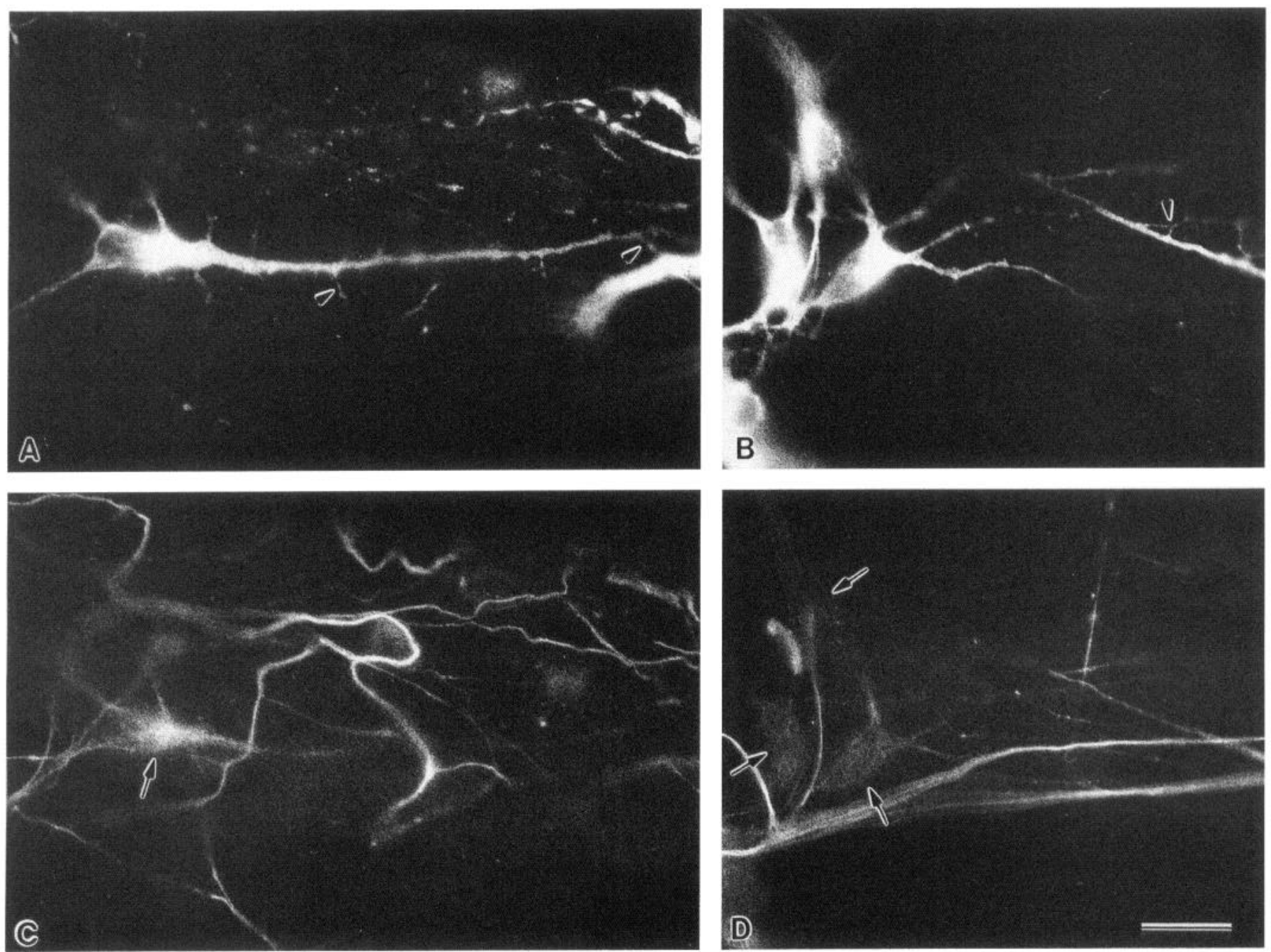

Figure 10. Labeling of dendritic processes and perikarya by antibodies against MAP2 $(A, B)$, compared to neuronal labeling with polyclonal antibodies against neurofilament subunits $(C, D)$ in a 2 d old coculture. MAP 2 antibodies strongly label the neuronal perikarya and the tapering dendrites, some of which show fine branches (arrowheads). The neurofilament antibodies label perikarya and dendrites variably (perikarya indicated with arrows) and usually less intensely than MAP2 antibodies, but strongly label many long, thin axons. Scale bar, $20 \mu \mathrm{m}$.

duction of AChR density along the neurite path within preexisting AChR aggregates that occur in areas of adhesion between myotube and substrate (Axelrod et al., 1976; Bloch and Geiger, 1980 ) and the de novo aggregation of AChRs along the course of neurites. In both cases, the myotube membrane opposite the neurite had a lower density of AChRs than the surrounding area. Additional evidence of the differentiation of this contact domain from that lateral to the neurite is found in the reduced concentrations of $43 \mathrm{kDa}$ protein, syntrophin and laminin, as well as the absence of the dense sarcolemmal specialization seen by electron microscopy. It is possible that specific molecules or structural specializations localized within a domain of close contact or adhesion between neurite and myotube inhibit the aggregation of AChRs there (see Bloch and Pumplin, 1988), while the primary or secondary signal(s) for aggregation reach the adjacent membrane regions, where there is no inhibition. It is also possible that local reduction in density of $\mathrm{AChR}$ and associated proteins results from the removal of ECM proteins by proteolysis. There is considerable evidence for the involvement of ECM in the formation and stabilization of AChR aggregates (Bloch and Pumplin, 1988) and growing neurites are known to externalize proteolytic activity (Krystosek and Seeds, 1984; Pittman 1985). On the other hand, elimination of preexisting heparan sulfate proteoglycan on the myocyte surface occurs along the neurite path and precedes the accumulation of AChRs and the deposition of new basal lamina molecules during synaptogenesis in Xenopus cocultures (Anderson, 1986). This and other results have led to the suggestion that such local proteolytic activity is involved in triggering $\mathrm{AChR}$ redistribution (Anderson, 1986; Anderson et al., 1991; Champaneria et al., 1992).

We observed a predominance of neurite-induced AChR redistribution on the surface of the myotubes facing the culture substrate (ventral surface). This phenomenon could be related to the accumulation of ECM molecules on the ventral surface of the myotubes. Molecules such as laminin, heparan sulfate proteoglycan, fibronectin and type IV collagen are concentrated at ventral AChR patches in cultured rat myotubes (Daniels et al., 1984; Dmytrenko et al., 1990) and ECM molecules such as laminin provide guidence cues for axons and promote their elongation (Bixby and Harris, 1991). On the other hand, some neurite-induced AChR aggregation occurred on the dorsal surface of myotubes where there is relatively little extracellular matrix under 

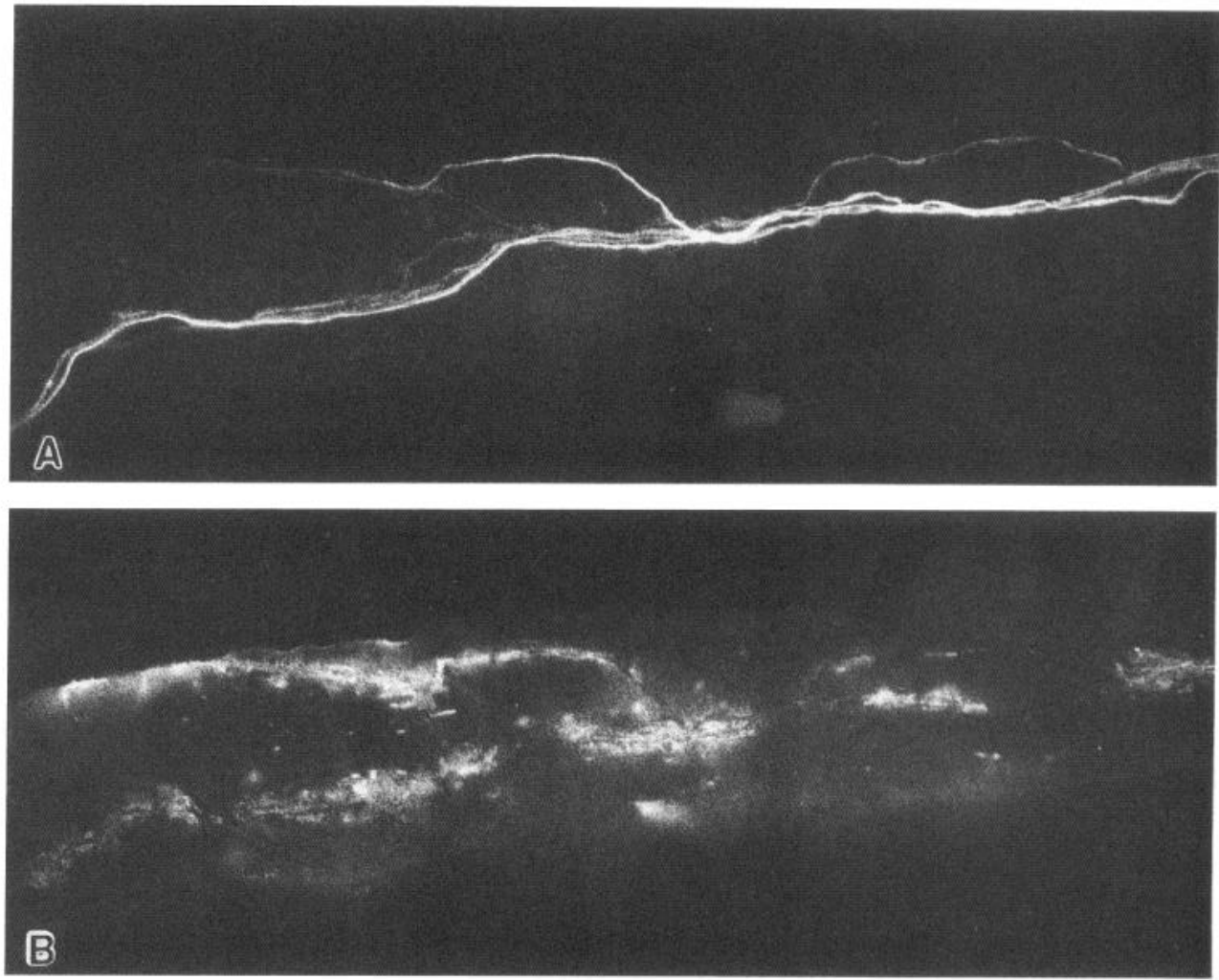

Figure 11. Association of newly-induced AChR aggregates with axons labeled by antibodies (SMI-31) against phosphorylated neurofilament $\mathrm{H}$ subunit $(A)$ and synaptophysin antibodies $(C, D)$. In $2 \mathrm{~d}$ old cocultures $(A, B)$, newly induced receptor aggregates $(B)$ are seen extensively along fasciculated and single axons labeled with antibody SMI-31. A similar pattern is seen in 2 d old cocultures labeled with synaptophysin antibodies $(C, E)$, except that fine punctate labeling is seen in the axon. In a $6 \mathrm{~d}$ old coculture $(D, F)$, synaptophysin shows a coarse, boutonlike distribution in an axon segment associated with a newly induced $\mathrm{AChR}$ aggregate. Arrows indicate the location of two boutons and the corresponding sites on the receptor aggregate. Scale bar, $20 \mu \mathrm{m}$.
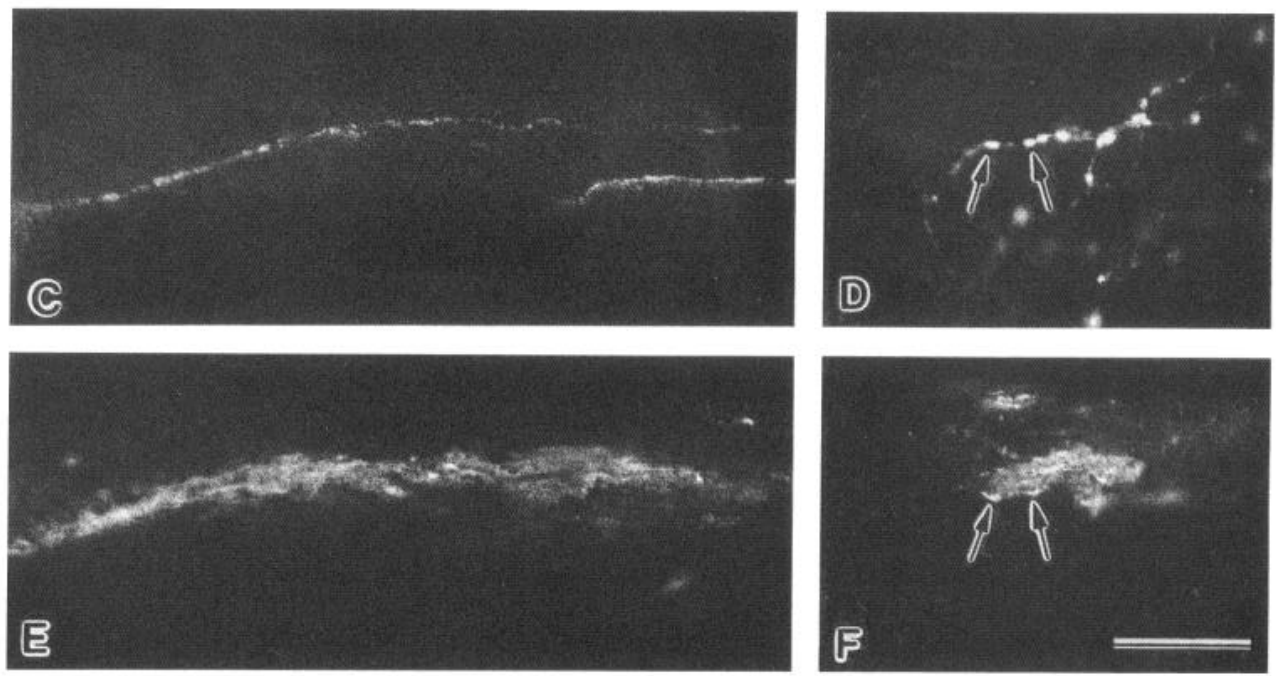

the culture conditions used here (Daniels et al., 1984; Olek et al., 1986; Daniels, unpublished observations), suggesting that extensive accumulation of ECM molecules is not a prerequisite for neurite-induced AChR aggregation.

Neurite-induced AChR aggregation in our system follows a time course similar to that in chick (Role et al., 1987) and Xenopus (Kidokoro et al., 1980) cocultures and appears to be due, at least in part, to the redistribution of preexisting receptors. AChR aggregates were detected as early as $6 \mathrm{hr}$ after plating dissociated VSC cells on myotubes. Since it takes at least a few hours for significant neurite extension to occur in these cultures, it is likely that detectable AChR redistribution occurred within a few hours after initial contact between neurites and myotubes. In any case our results are consistent with in vivo observations in the developing rat, where accumulation of receptors occurs within $1 \mathrm{~d}$ after the first signs of functional innervation (Bevan and Steinbach, 1977) and involves the redistribution of preexisting AChRs (Ziskind-Conhaim et al., 1984).

Cell type specificity. Neurons from the developing spinal cord and ciliary ganglion form functional synapses or induce synaptic structure upon contact with myotubes in Xenopus and chick cultures while those from the SCG and DRG have little capacity to do so (Cohen and Weldon, 1980; Role et al., 1985). Consistent with this, we found that cells isolated from the ventral half of the rat spinal cord induced AChR aggregation at sites of neurite contact more extensively than did neurons from other parts of the CNS and PNS. In this respect, it should be kept in mind that only about $10 \%$ of the neurons in the ventral spinal cords of fetal rats are motor neurons (Schaffner et al., 1987), which might suggest that the values we obtained would underestimate the 


\begin{tabular}{|c|c|c|c|}
\hline & $\begin{array}{l}\text { Total neurite } \\
\text { length }(\mu \mathrm{m})\end{array}$ & $\begin{array}{l}\text { Total neurite } \\
\text { length }(\mu \mathrm{m}) \\
\text { associated with } \\
\text { AChR aggregates }\end{array}$ & $\begin{array}{l}\% \text { Neurite length } \\
\text { associated with } \\
\text { AChR aggregates }\end{array}$ \\
\hline \multicolumn{4}{|c|}{ A. Cocultures with standard VSC neuron density ${ }^{a}$} \\
\hline Axon & $11,518.5$ & 3289.1 & $28.6(n=45)$ \\
\hline Dendrite & 5583.3 & 647.3 & $11.6(n=34)$ \\
\hline \multicolumn{4}{|c|}{$\begin{array}{l}\text { Aggregate-associated } \\
\text { dendrites fasciculated } \\
\text { with aggregate- }\end{array}$} \\
\hline associa & xons & 440.6 & $7.9(n=34)$ \\
\hline \multicolumn{4}{|c|}{$\begin{array}{l}\text { dendrites not } \\
\text { fasciculated with } \\
\text { aggregate-associated }\end{array}$} \\
\hline axons & & 206.7 & $3.7(n=34)$ \\
\hline \multicolumn{4}{|c|}{ B. Cocultures with low VSC neuron densityc } \\
\hline Axon & 2140 & \multicolumn{2}{|c|}{$27.2 \pm 4.6(\mathrm{SEM}, n=11)$} \\
\hline Dendrite & 963 & \multicolumn{2}{|c|}{$2.6 \pm 1.6(\mathrm{SEM}, n=11)$} \\
\hline
\end{tabular}

"Data in A were obtained from randomly selected fields in 2 d old cocultures that were plated with 50,000 VSC neurons per coverslip (see Materials and Methods). The values obtained did not fall into normal distributions (see Fig. 3 ); thus, no standard errors were calculated. The $n$ values are the number of fields examined.

"These aggregate-associated dendrites were fasciculated with axons that were associated with newly induced aggregates where the axons extended beyond the dendrite segment.

- Data in B were obtained from individually traced neuron-myotube contacts that showed induced AChR aggregation in $2 \mathrm{~d}$ old cocultures plated with 4000 VSC neurons per coverslip (see Materials and Methods). The $n$ value is the number of neurons traced.

aggregating activity of these cells. On the other hand, the axons of motor neurons were likely to be fasciculated with axons or dendrites of other neurons that might not be expected to form synapses with muscle. This fasciculation would lead to an underestimate of neurite length in contact with myotubes, and thus an ovcrestimate of the aggregating activity of all VSC neurons. In fact, when low density VSC-muscle cocultures were assayed, we found that only a fraction of the neurons induced AChR aggregation at sites of contact with myotubes, but that the percent of axon length in contact with myotubes that was associated with induced aggregates in active cells was about $27 \%$. This is of the same order as the values for the entire population of neurites as measured in higher density VSC-muscle cocultures. The observation that neurons from SCG, DRG and hippocampus did induce significant levels of AChR aggregation suggests that they may express signals for synapse formation, such as agrin (although it is unlikely that the $\mathrm{AChR}$ aggregates induced by these predominantly noncholinergic cells represent functional synaptic sites). Isoforms of agrin that have AChR aggregating activity when expressed in vitro have been found in various regions of the CNS as well as the dorsal root- and ciliary ganglia (Fcrns ct al., 1993; Hoch et al., 1993; Thomas et al., 1993; Ma et al., 1994). On the other hand, in Xenopus cocultures DRG neurons failed to deposit agrin on a substrate that did bind agrin from spinal neurons of the same species (Cohen et al., 1994), in agreement with the specificity of AChR aggregation ability in that system. The possibility that a molecule such as agrin is used by a variety of neurons as a synapse formation signal calls for additional studies of agrin expression in neuronal and nervemuscle cocultures.

Structural differentiation at sites of neurite-induced $A C h R$ aggregation. In 1-2 d old cocultures, both $43 \mathrm{kDa}$ protein and syntrophin were colocalized with aggregated AChRs, in agreement with the observation of dense sarcolemmal specializations at these sites. Colocalization of laminin with aggregated AChRs was more variable, as was the appearance of basal lamina. This distribution of proteins and structures is consistent with postsynaptic differentiation (Froehner, 1993; Hall and Sanes, 1993) but it should be noted that similar differentiation of the myotube surface occurs at sites of AChR aggregation induced by a variety of stimuli other than innervation (Salpeter et al., 1982; Peng and Cheng, 1982; Peng and Froehner, 1985; Olek et al., 1986; Bloch and Pumplin, 1988; Daniels, 1990; Daniels et al., 1990).

In 1-2 d old cocultures, we found evidence of a very early stage of presynaptic development at sites of contact between neurites and myotubes. Labeling with synaptophysin antibodies showed a relatively even distribution of punctate immunoreactivity in the axons. This agreed well with the sparse distribution of synaptic vesicles observed in thin sections. A characteristic feature of newly induced AChR aggregation sites at this stage was frequent close contact between the axon and myotube, reminiscent of the earliest rat NMJs observed in vivo (Kelly and Zachs, 1969) and in vitro (Nakajima et al., 1980). In the present study, the tendency of the axon to be partially or completely surrounded by the myotube surface was particularly suggestive of a strong adhesive interaction between the two cells. This apparent adhesive interaction and the adjacent formation of postsynaptic-like specializations occurred more prominently in the present study than in previous reports. The relationship between these phenomena deserves further study (see Bloch and Pumplin, 1988).

Examination of neurite-induced AChR aggregation sites in six day old cocultures provided evidence of continuing synaptic development. Synaptophysin now appeared in a coarse punctate pattern, suggestive of synaptic boutons, in agreement with the uptake of FMI-43 under depolarizing conditions. Electron microscopic observations of such uptake sites within induced AChR aggregates revealed stuctural specializations indicative of a more mature, functional NMJ (Kelly and Zacks, 1969; Hall and Sanes, 1993). Thus, our results suggest that the sites of neurite-induced $\mathrm{AChR}$ aggregation are indeed developing synapses.

Neuronal polarity in neurite-induced AChR aggregation. In culture, neuronal polarity, that is, the development of distinct molecular, structural, and functional properties in the axonal and dendro-somatic domains, has been demonstrated in neurons from several tissues and brain regions (Craig and Banker, 1994). Although neuromuscular junctions in vivo are formed only by axons of motor neurons, little is known about the distribution of signaling molecules required to induce development of this synapse. Role et al. (1985) suggested that both axons and dendrites (defined only by morphological criteria) of chick motor neurons in culture could induce AChR clusters on myotubes. Berman et al. (1993) reported that $\mathrm{G} \Lambda \mathrm{P} 43$, an axonal marker protein, was present in chick ciliary ganglion cell neurites that were associated with AChR clusters in cocultures, but did not examine the ability of dendrites to induce receptor clusters. Neuronal polarity in our culture system was established by use of well-known molecular markers as well as observation of characteristic axonal and dendritic morphology. Although MAP2 was not com- 


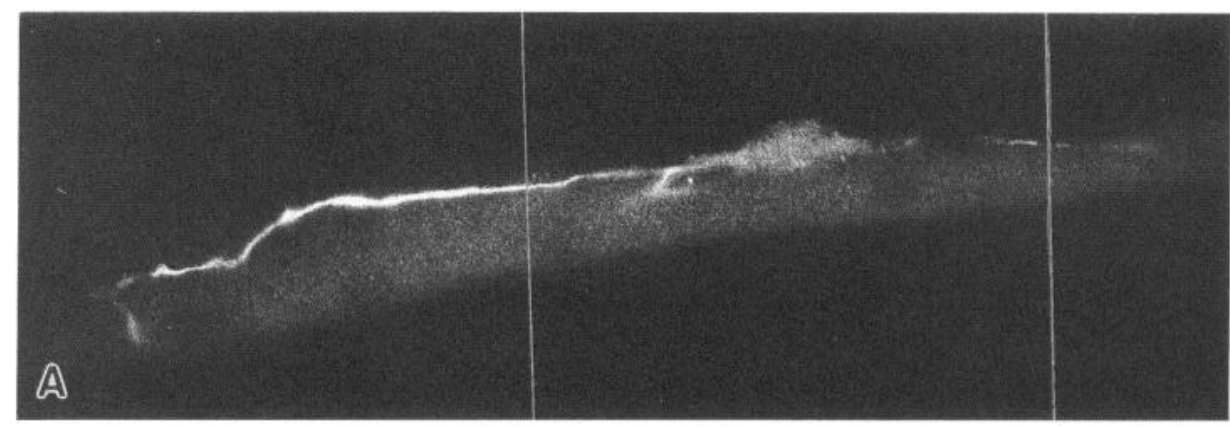

Figure 12. Association of newly induced $\mathrm{AChR}$ aggregates with axons, as opposed to dendrites. Two day old cocultures with a low density of VSC neurons were labeled with TRITC-BTX $(B)$, a monoclonal antibody against MAP2 $(C)$ and polyclonal antibodies against neurofilament subunits $(A)$, followed by appropriate secondary antibodies. A neuron in contact with a myotube has extended a relatively short axon that is strongly labeled with neurofilament antibodies but weakly labeled with MAP2 antibodies, as well as two dendrites that are clearly MAP2 positive. The shorter dendrite serves as the base of the axon. Induced AChR aggregation is seen only along the distal portion of the axon. The montages were made from micrographs taken in two focal planes to show the neurites more clearly. Scale bar, $20 \mu \mathrm{m}$.
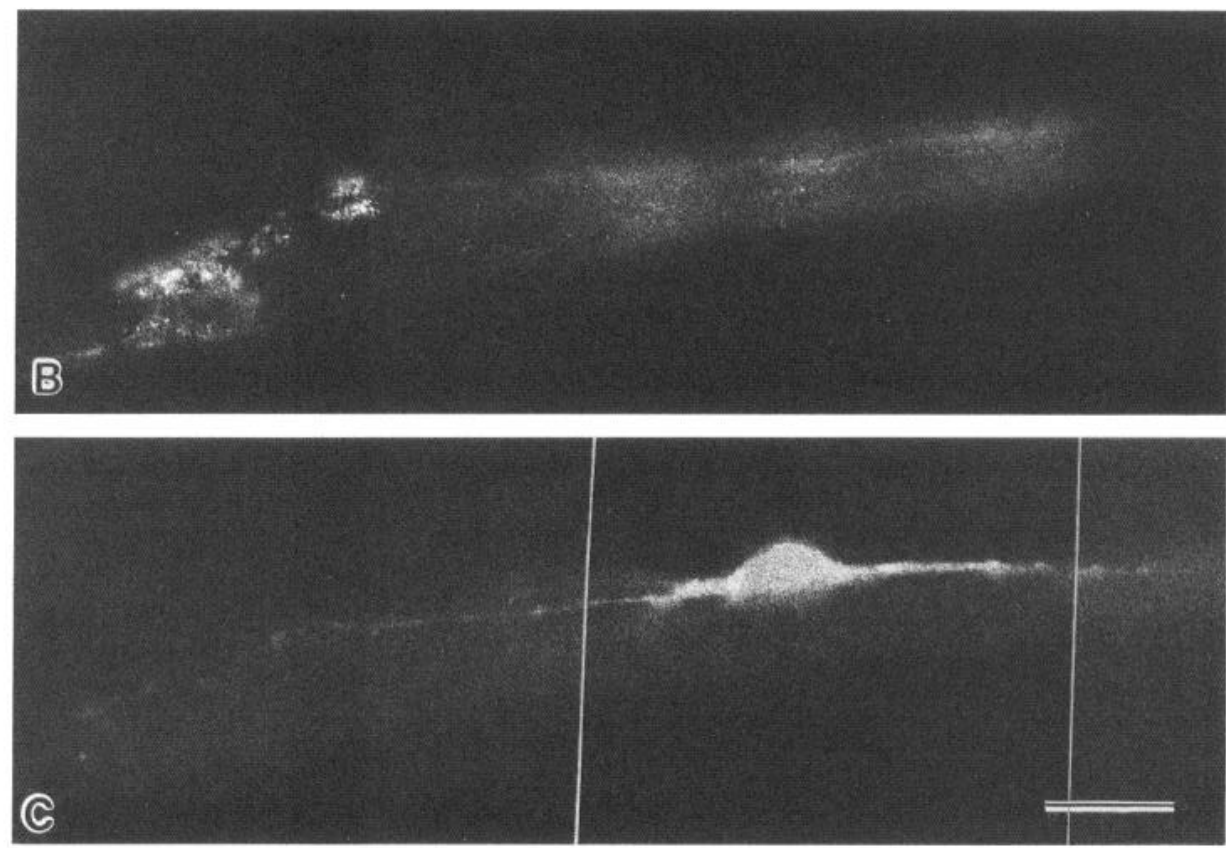

pletely excluded from axons at two days of coculture (see Kosik and Finch, 1987), the low intensity of MAP2 labeling compared to that in the soma and dendrites, taken together with the distinctive morphology of the two types of processes, made it easy to distinguish axon from dendrite. Our results suggest that developing axons are 10-fold more effective than developing dendrites in the induction of AChR aggregation. The low level of $\mathrm{AChR}$ aggregation apparently induced by the dendrites might be accounted for by incomplete development of neuronal polarity at the stage examined, as indicated by the residual MAP2 staining in axons. It has also been reported that some proteins found in a polarized distribution in vivo are often not well segregated in vitro (Craig and Banker, 1994). Thus, we have provided the first evidence that one or more of the signaling molecules required for the induction of postsynaptic development at the NMJ are expressed preferentially by axons, and that this polarized expression occurs at a relatively early stage of neurite differentiation. It will be of considerable interest to examine the distribution of putative signaling molecules for postsynaptic differentiation on VSC neurons in culture to determine whether their transport, secretion or expression on the cell surface is targeted to axons. Additionally, we may further our understanding of the mechanisms involved in synaptogenesis by comparing axons and dendrites with respect to their interactions (for example, adhesion, local proteolysis, retrograde signaling) with myotubes.

\section{References}

Adams ME, Butler MH, Dwyer TM, Peters MR, Murnane AA, Froehner SC (1993) Two forms of mouse syntrophin, a $58 \mathrm{kd}$ dystrophinassociated protein, differ in primary structure and tissue distribution. Neuron 11:531-540.

Anderson MJ (1986) Nerve-induced remodeling of muscle basal lamina during synaptogenesis. J Cell Biol 102:863-877.

Anderson MJ, Cohen MW (1977) Nerve-induced and spontaneous redistribution of acetylcholine receptors on cultured muscle cells. J Physiol (Lond) 268:757-773.

Anderson MJ, Fambrough DM (1983) Aggregates of acetylcholine receptors are associated with plaques of a basal lamina heparan sulfate proteoglycan on the surface of skeletal muscle fibers. J Cell Biol 97: $1396-1411$.

Anderson MJ, Cohen MW, Zorychta E (1977) Effects of innervation on the distribution of acetylcholine receptors on cultured muscle cells. J Physiol (Lond) 268:731-756.

Anderson MJ, Champaneria S, Swenarchuk LE (1991) Synaptic differentiation can be evoked by polymer microbeads that mimic localized pericellular proteolysis by removing proteins from adjacent surfaces. Dev Biol 147:464-479.

Axelrod D, Ravdin P, Koppel DE, Schlessinger J, Webb WW, Elson El, Podleski TR (1976) Lateral motion of fluorescently-labelled acetylcholine receptors in the membrane of developing muscle fibers. Proc Natl Acad Sci USA 73:4594-4598.

Berman SA, Moss D, Bursztajn S (1993) Axonal branching and growth cone structure depend on target cells. Dev Biol 159:153-162.

Betz WJ, Mao F, Bewick GS (1992) Activity dependent fluorescent staining and destaining of living motor nerve terminals. J Neurosci 12:363-375.

Bevan S, Steinbach JH (1977) The distribution of $\alpha$-bungarotoxin bind- 
ing sites on mammalian skeletal muscle developing in vivo. J Physiol (Lond) 267:195-213

Bixby JL, Harris WA (1991) Molecular mechanisms of axon growth and guidance. Annu Rev Ccll Biol 7:117-159.

Bloch RJ, Froehner SC (1987) The relationship of the postsynaptic $43 \mathrm{~K}$ protein to acetylcholine receptors in receptor clusters isolated from cultured rat myotubes. J Cell Biol 104:645-654.

Bloch RJ, Geiger B (1980) The localization of acetylcholine receptor clusters in areas of cell-substrate contact in cultures of rat myotubes. Cell $21: 25-35$.

Bloch RJ, Pumplin DW (1988) Molecular events in synaptogenesis: nerve-muscle adhesion and postsynaptic differentiation. J Physiol 254(Cell Physiol 23):C345-C364.

Caceres A, Binder LI, Payne MR, Bender P, Rebhun L, Steward O (1984) Differential subcellular localization of tubulin and the microtubule-associated protein MAP2 in brain tissue as revealed by immunocytochemistry with monoclonal hybridoma antibodies. J Neurosci 4:394-410.

Champaneria S, Swenarchuk LE, Anderson MJ (1992) Increases in pericellular proteolysis at developing neuromuscular junctions in culture. Dev Biol 149:261-277.

Chiu AY, Sanes JR (1984) Development of basal lamina in synaptic and extrasynaptic portions of embryonic rat muscle. Dev Biol 103: 456-467.

Cohen MW, Godfrey EW (1992) Early appearance of and neuronal contribution to agrin-like molecules at embryonic frog nerve-muscle synapses formed in culture. J Neurosci 12:2982-2992.

Cohen MW, Weldon PR (1980) Localization of acetylcholine receptors and synaptic ultrastructure at nerve-musclc contacts in culture: dependence on nerve type. J Cell Biol 86:388-401.

Cohen MW, Anderson MJ, Zorychta E, Weldon PR (1979) Accumulation of acetylcholine receptors at nerve-muscle contacts in culture. Prog Brain Res 49:335-349.

Cohen MW, Moody-Corbett F, Godfrey EW (1994) Neuritic deposition of agrin on culture substrate: implications for nerve-muscle synaptogenesis. J Neurosci 14:3293-3303

Craig AM, Banker G (1994) Neuronal polarity. Annu Rev Neurosci 17:267-310.

Daniels MP (1990) Localization of actin, $\beta$-spectrin, $43 \times 103 \mathrm{M}_{\mathrm{r}}$ and $58 \times 103 \mathrm{M}_{\mathrm{r}}$ proteins to receptor-enriched domains of newly formed acetylcholine receptor aggregates in isolated myotube membranes. $\mathrm{J}$ Cell Sci 97:615-627.

Daniels MP, Vigny M. Sonderegger P, Bauer H-C, Vogel Z (1984) Association of laminin and other basement membrane components with regions of high acetylcholine receptor density on cultured myotubes. Int J Dev Neurosci 2:87-99.

Daniels MP, Krikorian JG, Olek AJ, Bloch RJ (1990) Association of cytoskeletal proteins with newly formed acetylcholine receptor aggregates induced by embryonic brain extract. Exp Cell Res 186:99108 .

Davey DF, Cohen MW (1986) Localization of acetylcholine receptors and cholinesterase on nerve-contacted and noncontacted muscle cells grown in the presence of agents that block action potentials. J Neurosei 6:673-680.

Dmytrenko GM, Scher MG, Poiana G, Baetscher M, Bloch RJ (1990) Extracellular glycoproteins at acetylcholine receptor clusters of rat myotubes are organized into domains. Exp Cell Kes 189:41-50.

Ferns MJ, Campanelli JT, Hoch W, Scheller RH, Hall Z (1993) The ability of agrin to cluster AChRs depends on alternative splicing and on cell surface proteoglycans. Neuron 11:491-502.

Fitzgerald SC (1989) Dissociated spinal cord-dorsal root ganglion cultures on plastic tissue culture dishes and glass coverslips and wells. In: A dissection and tissue culture manual of the nervous system (Shahar A, deVellis J, Vernadakis A, Haber B, eds), pp 219-222. New York: Liss.

Frank E, Fischbach GD (1979) Early events in neuromuscular junction formation in vitro. Induction of acetylcholine receptor clusters in the postsynaptic membrane and morphology of newly formed synapses. J Cell Biol 83:143-158.

Froehner S (1984) Peripheral proteins of postsynaptic membranes from Torpedo electric organ identified with monoclonal antibodies. J Cell Biol 99:88-96.

Frnehner S (1993) Regulation of ion channel distribution at synapses. Annu Rev Neurosci 16:347-368.

Froehner S, Murnane AA, Tobler M, Peng HB, Sealock R (1987) A postsynaptic $\mathrm{Mr} 58,000(58 \mathrm{~K})$ protein concentrated at acetylcholine receptor-rich sites in Torpedo electroplaques and skeletal muscle. J Cell Biol 104:1633-1646.

Godfrey EW, Siebenlist RE, Wallskog PA, Walters LM, Bolender DL, Yorde DE (1988) Basal lamina components are concentrated in premuscle masses and at early acetylcholine receptor clusters in chick embryo hindlimb muscles. Dev Biol 130:471-486.

Goslin K, Banker G (1991) Rat hippocampal neurons in low-density culture. In: Culturing nerve cells (Banker G, Goslin K, eds), pp 251281. Cambridge, MA: MIT Press.

Grainger F, James DW, Tresman RL (1968) An electron-microscopic study of the early outgrowth from chick spinal cord in vitro. Z Zellforsch 90:53-67.

Guthrie PB, Brenneman DE, Neale EA (1987) Morphological and biochemical differences expressed in separate dissociated cell cultures of dorsal and vental halves of the mouse spinal cord. Brain Res 420: $313-323$.

Hall ZW, Sanes JR (1993) Synaptic structure and development: the neuromuscular junction. Cell 72/Neuron 10:99-121.

Harris J, Ayyub C, Shaw G (1991) A molecular dissection of the carboxyterminal tails of the major neurofilament subunits NF-M and NFH. J Neurosci Res 30:47-62.

Higgins D, Lein PJ, Osterhout DJ, Johnson MI (1991) Tissue culture of mammalian autonomic neurons. In: Culturing nerve cells (Banker G, Goslin K, eds), pp 177-205. Cambridge, MA: MIT Press.

Hoch W, Ferns M, Campanelli IT, Hall ZW, Scheller RH (1993) Developmental regulation of highly active alternatively spliced forms of agrin. Neuron 11:479-490.

Kelly AM, Zacks SI (1969) The fine structure of motor endplate mor phogenesis. J Cell Biol 42:154-169.

Kidokoro Y (1980) Developmental changes of spontaneous synaptic potential properties in the rat neuromuscular contact formed in culture. Dev Biol 78:231-241

Kidokoro Y, Heinemann S, Schubert B, Brandt L, Klier FG (1976) Synapse formation and neurotrophic effects on muscle cell lines. Cold Spring Harbor Symp Quant Biol 40:373-388.

Kidokoro Y, Anderson MJ, and Gruener R (1980). Changes in synaptic potential properties during acetylcholine receptor accumulation and neurospecific interactions in Xenopus nerve-muscle cell culture. Dev Biol 78:464 483.

Kosik KS, Finch EA (1987) MAP2 and tau segregate into dendritic and axonal domains after the elaboration of morphologically distinct neurites: an immunocytochemical study of cultured rat cerebrum. J Neurosci 7:3124-3153.

Krystosek A, Seeds NW (1984) Peripheral neurons and Schwann cells secrete plasminogen activator. J Cell Biol 98:773-776.

Lieth E, Fallon JR (1993) Muscle agrin: neural regulation and localization at nerve-induced acetylcholine receptor clusters. J Neurosci $13: 2509-2514$.

Lupa MT, Gordon H, Hall ZW (1990) A specific effect of muscle cells on the distribution of presynaptic proteins in neurites and its absence in a C2 muscle cell variant. Dev Biol 142:31-43.

Lyser KM (1968) Early differentiation of motor neuroblasts in the chick embryo as studied by electron microscopy. II. Microtubules and neurofilaments. Dev Biol 17:117-142.

Ma E, Morgan R, Godfrey EW (1994) Distribution of agrin mRNAs in the chick embryo nervous system. J Neurosci 14:294.3-2952.

Matus A, Bernhardt R, Hugh-Jones T (1981) High molecular weight microtubule associated proteins are preferentially associated with dendritic microtubules in brain. Proc Natl Acad Sci USA 78:30103014.

Melton MA, Yu N-Y, Dutton EK, Olek AJ (1993) Local induction of acetylcholine receptor aggregates on cultured rat myotubes by a partially purified protein from fetal pig brain. Exp Cell Res 208:378386.

Nakajima Y, Kidokoro Y, Klier FG (1980) The development of functional neuromuscular junctions in vitro: an ultrastructural and physiological study. Dev Biol 77:52-72.

Olek AJ, Ling A, Daniels MP (1986) Development of ultrastructural specializations during the formation of acetylcholine receptor aggregates on cultured myotubes. J Neurosci 6:487-497.

Peng HB, Cheng P-C (1982) Formation of postsynaptic specializations induced by latex beads in cultured muscle cells. J Neurosci 2:17601774.

Peng HB, Froehner SC (1985) Association of the postsynaptic $43 \mathrm{~K}$ 
protein with newly formed acetylcholine receptor clusters in cultured muscle cells. J Cell Biol 100:1698-1705.

Peng HB, Nakajima Y, Bridgman PC (1980) Development of the postsynaptic membrane in Xenopus neuromuscular cultures observed by freeze-fracture and thin-section electron microscopy. Brain Res 196: $11-31$.

Pittmann RN (1985) Release of plasminogen activator and a calciumdependent metalloprotease from cultured sympathetic and sensory neurons. Dev Biol 110:91-101.

Pumplin DW (1989) Acetylcholine receptor clusters of rat myotubes have at least three domains with distinctive cytoskeletal and membranous components. J Cell Biol 109:739-753.

Rees RP, Bunge MB, Bunge RP (1976) Morphological changes in the neuritic growth cone and target neuron during synaptic junction development in culture. J Cell Biol 68:240-263.

Role LW, Matossian VR, O'Brien RJ, Fischbach GD (1985) On the mechanism of acetylcholine receptor accumulation at newly formed synapses on chick myotubes. J Neurosci 5:2197-2204.

Role LW, Roufa DG, Fischbach GD (1987) The distribution of acetylcholine receptor clusters and sites of transmitter release along chick ciliary ganglion neurite-myotube contacts in culture. J Cell Biol 104: 371-379.

Ryan TA, Reuter H, Wendland B, Schweizer FE, Tsien RW, Smith SJ (1993) The kinetics of synaptic vesicle recycling measured at single presynaptic boutons. Neuron 11:713-724.

Salpeter MM, Spanton S, Holley K, Podleski TR (1982) Brain extract causes acetylcholine receptor redistribution which mimics some early events at developing neuromuscular junctions. J Cell Biol 93:417425.

Sanderson RD, Fitch JM, Linsenmeyer TR, Mayne R (1986) Fibro- blasts promote the formation of a continuous hasal lamina during myogenesis in vitro. J Cell Biol 102:740-747.

Schaffner AE, Daniels MP (1982) Conditioned medium from cultures of embryonic neurons contains a high molecular weight factor which induces acetylcholine receptor aggregation on cultured myotubes. J Neurosci 2:623-632.

Schaffner AE, St. John PA, Barker JL (1987) Fluorescence-activated cell sorting of embryonic mouse and rat motoneurons and their longterm survival in vitro. J Neurosci 7:3088-3104.

Shimada Y, Fischman DA, Moscona AA (1969) Formation of neuromuscular junctions in embryonic cell cultures. Proc Natl Acad Sci USA 62:715-721.

Sternberger LA, Sternberger NH (1983) Monoclonal antibodies distinguish phosphorylated and non-phosphorylated forms of neurofilaments in situ. Proc Natl Acad Sci USA 80:6126-6130.

Thomas WS, O'Dowd DK, Smith MA (1993) Developmental expression and alternative splicing of chick agrin RNA. Dev Biol 158:523535.

Tucker RP (1990) The roles of microtubule-associated proteins in brain morphogenesis: a review. Brain Res Rev 15:101-120.

Walton MK, Schaffner AE, Barker JL (1993) Sodium channels, GA$\mathrm{BAa}$ receptors, and glutamate receptors develop sequentially on embryonic rat spinal cord cells. J Neurosci 13:2068-2084.

Weldon PR, Cohen MW (1979) Development of synaptic ultrastructure at neuromuscular contacts in an amphibian cell culture system. J Neurocytol 8:239-259.

Wiedenmann R, Franke WW (1985) Identification and localization of synaptophysin, an integral membrane glycoprotein of $\mathrm{Mr} 38,000$ characteristic of presynaptic vesicles. Cell 41:1017-1028.

Ziskind-Conhaim L, Geffen I, Hall ZW (1984) Redistribution of acetylcholine receptors on developing rat myotubes. J Neurosci 4:23462349. 